ARTICLE TYPE

\title{
Fluorinated mixed valence Fe(II)-Fe(III) phosphites with channels templated by linear tetramine chains. Structural and magnetic implications of partial replacement of $\mathrm{Fe}(\mathrm{II})$ by $\mathrm{Co}(\mathrm{II})$.
}

\author{
Joseba Orive, ${ }^{a}$ Roberto Fernández de Luis, ${ }^{a}$ Jesús Rodríguez Fernández, ${ }^{\text {b }}$ Estibaliz Legarra, ${ }^{c}$ Fernando \\ Plazaola, ${ }^{\mathrm{c}}$ María I. Arriortua ${ }^{\mathrm{a}, *}$ \\ Received (in XXX, XXX) Xth XXXXXXXXX 20XX, Accepted Xth XXXXXXXXX 20XX \\ DOI: $10.1039 / b 000000 x$
}

Three new fluorinated mixed valence $\mathrm{Fe}(\mathrm{II})-\mathrm{Fe}(\mathrm{III})$ phosphites were synthesized employing mild hydrothermal conditions. $\left(\mathrm{H}_{4} \text { baepn }\right)_{0.5}\left[\mathrm{Fe}^{\mathrm{III}}{ }_{2.3} \mathrm{Fe}^{\mathrm{II}}{ }_{1.7}\left(\mathrm{H}_{2} \mathrm{O}\right)_{2}\left(\mathrm{HPO}_{3}\right)_{4-(\mathrm{x}+\mathrm{y})}\left(\mathrm{HPO}_{4}\right)_{\mathrm{x}}\left(\mathrm{PO}_{4}\right)_{\mathrm{y}} \mathrm{F}_{4}\right](\mathrm{x} \simeq 0.13, \mathrm{y} \simeq 0.3)$

101 (baepn = N,N'-Bis(2-aminoethyl)-1,3-propanediamine $\left(\mathrm{C}_{7} \mathrm{~N}_{4} \mathrm{H}_{20}\right)$ ) and the $\mathrm{Co}(\mathrm{II})$-substituted phase with formula $\left(\mathrm{H}_{4} \text { baepn }\right)_{0.5}\left[\mathrm{Fe}^{\mathrm{III}}{ }_{2.0} \mathrm{Fe}^{\text {II }}{ }_{0.71} \mathrm{Co}_{1.29}{ }^{\text {II }}\left(\mathrm{H}_{2} \mathrm{O}\right)_{2}\left(\mathrm{HPO}_{3}\right)_{4-\mathrm{x}}\left(\mathrm{HPO}_{4}\right)_{\mathrm{x}} \mathrm{F}_{4}\right](\mathrm{x} \simeq 0.38) 2$ were studied by single crystal X-ray diffraction. The phase with the major content of $\mathrm{Co}(\mathrm{II})$,

$\left(\mathrm{H}_{4} \text { baepn }\right)_{0.5}\left[\mathrm{Fe}^{\mathrm{III}}{ }_{2.0} \mathrm{Fe}^{\mathrm{II}}{ }_{0.62} \mathrm{Co}^{\mathrm{II}}{ }_{1.38}\left(\mathrm{H}_{2} \mathrm{O}\right)_{2}\left(\mathrm{HPO}_{3}\right)_{4-\mathrm{x}}\left(\mathrm{HPO}_{4}\right)_{\mathrm{x}} \mathrm{F}_{4}\right](\mathrm{x} \simeq 0.38) 3$ was achieved as polycrystalline powder and studied by Rietveld refinement by using the structural model of $\mathbf{2}$. These compounds have 15 been characterized by ICP-Q-MS, thermogravimetric and thermodiffractometric analyses, and XPS, IR, $\mathrm{UV} /$ vis and Mössbauer spectroscopies. Single crystal data indicate that phases $\mathbf{1}$ and $\mathbf{2}$ crystallize in the $\mathrm{P} 2{ }_{1} / \mathrm{c}$ space group with lattice parameters: $\mathrm{a}=13.6808(4), \mathrm{b}=12.6340(2), \mathrm{c}=12.7830(3) \AA$ and $\beta=$ $116.983(4)^{\circ}$ for $\mathbf{1}$ and $\mathrm{a}=13.6823(4), \mathrm{b}=12.6063(3), \mathrm{c}=12.7535(4) \AA$ and $\beta=116.988(4)^{\circ}$ for $\mathbf{2}$, with $\mathrm{Z}=$ 4. Reciprocal space of 1 shows satellite reflections with a modulation wavevector $q=0.284(2) \mathrm{a}^{*}$ which 20 indicate an incommensurate long-range order. The average structure of these compounds is built up by a 3D lattice constructed by inorganic layers of $\mathrm{Fe}(\mathrm{III})$ chains and $\mathrm{Fe}(\mathrm{II}), \mathrm{Co}$ (II) dimers joined by phosphite groups partially substituted by $\mathrm{HPO}_{4}$ and $\mathrm{PO}_{4}$ tetrahedral groups. These anionic layers stack along the [100] direction encapsulating linear tetramines into eight-membered open channels involving host-guest interaction. Magnetic measurements of $\mathbf{1}$ and $\mathbf{3}$ show an antiferromagnetic coupling as the major

25 interactions, exhibiting a weak ferromagnetic component together with a spin glass transition at low temperature in case of $\mathbf{1}$. Heat capacity measurements show a small anomaly at $20.5 \mathrm{~K}$ for $\mathbf{1}$ and a sharp magnetic peak at $28 \mathrm{~K}$ for $\mathbf{3}$. Unexpectedly, the small anomaly observed in $\mathbf{1}$ grows with the magnetic field and becomes better defined.

\section{Introduction}

${ }_{30}$ One of the challenges to be faced in the field of open framework materials science and technology is the design and the obtaining of porous compounds which combine the classical properties of the zeolites with physicochemical properties such as magnetic, optical or conductive, arising from the introduction of transition 35 metals in the crystalline structures. ${ }^{1,2}$

Synthesis of microporous materials such as zeolites, aluminosilicates and phosphates or other zeotypes, which receive interest because of their potential industrial applications as solid acid catalysts, ion exchangers or in the separation of gases ${ }^{2,3}$, is driven 40 sometimes by using protonated amines as templates or structure directing agents (SDAs). ${ }^{4}$

By employing small organic amines as structure-directing agents, such as n-propylamine, n-butylamine, cyclopentylamine and cyclohexylamine extra-large-micropore compounds, for 45 instance 16 and 18 -membered-ring fluorinated gallium phosphates, ${ }^{5}$ 16-ring channels vanadium(III) phosphites $^{6}$ and 24- ring channels zinc phosphites ${ }^{7}$ have been hydrothermally achieved. The crystallization of them is given by a cooperative templating mechanism of multiple organic cations which reside 50 within the voids with their hydrophobic groups pointing toward the center of the pores and the hydrophilic $\mathrm{NH}_{3}{ }^{+}$ends interacting via hydrogen bonding with the host.

The assembly of small organic amines and their effect as SDA to direct the crystallization of large micropore aluminophosphites, 55 zincophosphates, and aluminophosphates has also been investigated. The authors conclude that the aggregation of 1,6hexanediamine (HDA) molecules gives rise to the formation of lamellar structures, while microporous 3D frameworks are formed mainly from the host-guest interaction between inorganic ${ }_{60}$ frameworks and individual 1,6-HDA. ${ }^{8}$

Recently, some gallium zincophosphites, NTHU-13, with channel expansion from 24-ring to 72-ring were successfully achieved by using heterometal centers and a series of aliphatic monoamines increasing the template from 4-carbon (4C) 
containing butylamine to $18 \mathrm{C}$ octadecylamine. 9

According to the host guest charge matching concept a highly charged inorganic framework should be templated by highly charged organic amines such as multiamines. ${ }^{10}$ For instance, the 5 chain-type polyamines such as TETA (10-atom-skeleton tetramine $)^{11}$, AE-DAP (8-atom-skeleton triamine) $)^{12}$ and 1,6-HDA (8-atom-skeleton diamine $)^{13}$ conducted to the crystallization of $\left(\mathrm{C}_{6} \mathrm{H}_{22} \mathrm{~N}_{4}\right)_{0.5}\left[\mathrm{Zn}_{3}\left(\mathrm{HPO}_{4}\right)\left(\mathrm{PO}_{4}\right)_{2}\right]$ (16R-channel structure with $25.6 \%$ non framework space (NFS)), ${ }_{10}\left(\mathrm{C}_{5} \mathrm{H}_{18} \mathrm{~N}_{3}\right)_{0.5}\left[\mathrm{Zn}_{3}\left(\mathrm{HPO}_{4}\right)_{3}\left(\mathrm{PO}_{4}\right)\right] \quad$ (16R-channel structure with $36.2 \%$ NFS) and $\left(\mathrm{C}_{6} \mathrm{H}_{18} \mathrm{~N}_{2}\right)\left[\mathrm{Zn}_{4}\left(\mathrm{PO}_{4}\right)_{2}\left(\mathrm{HPO}_{4}\right)_{2}\right] \cdot 3 \mathrm{H}_{2} \mathrm{O}$ (20Rchannel structure with $45.7 \%$ NFS) respectively. The role of such templates indicated that the size effect of a polyamine template is reduced with increasing number of amino groups and that NFS in

15 the structures increases in proportion to the channel size. However, W-M. Chang et al. observed opposite template effects for the synthesis of zinc phosphates with 16R channel structures by using linear triamine and pentamine molecules. They concluded that the NFS is substantially augmented with 20 increasing length and amino groups in the template. ${ }^{14}$

Even today the specific templating role of the SDAs is not clear. In fact, the 'true' templating effect referring to a direct correlation between the van der Waals shape of the organic template and the channel space of the resultant inorganic 25 framework is not very usual. ${ }^{15}$ In that regard, computer modeling has demonstrated to be a useful tool for examining nonbonding interaction energies of different host-guest systems. ${ }^{16}$

In spite of the scientific community has made progress in the rational organic SDAs-mediated synthesis of zeolitic inorganic 30 open framework materials, ${ }^{4}$ the complex chemical reaction mechanisms in which the inorganic buildings nucleate around the organic cationic species are still poorly understood. Actually, there are many examples in which the SDAs represent the products of the initial organic precursors transformed during the 35 hydrothermal synthesis by means of hydrolysis of linear polyamines, ${ }^{17}$ decomposition of amides $^{18}$ or $\mathrm{N}$-alkylation reactions. ${ }^{19}$ Therefore, because of the large number of parameters involved in the reaction processes still make the rational approach to the synthesis of these materials a challenging 40 task, the "trial-and-error" strategy becomes necessary to explore new architectures when new organic templates are being used.

On the other hand, the totally or partially replacement of the classical four-coordinated $\mathrm{PO}_{4}{ }^{3-}$ building units by 3-connected groups such as the pseudo-pyramidal $\mathrm{HPO}_{3}{ }^{2-}$ blocks, gives rise 45 to different connectivity patterns which can favor the construction of open structures with novel topologies and lower framework densities. ${ }^{20}$ Moreover, the networks containing transition metal ions with open $d$ shells turn out to be attractive due to their potential magnetic properties. More

so specifically, mixed-valent iron-containing compounds may exhibit interesting magnetic behaviour such as ferrimagnetism, ${ }^{21}$ spin glass state $^{22,23}$ or spin canted antiferromagnetism. ${ }^{24}$ In particular, literature refers to the existence of two examples of mixed-valent iron purely inorganic ${ }_{55}$ phosphites, $\quad \mathrm{Li}_{1.43}\left[\mathrm{Fe}_{4.43}^{\mathrm{II}} \mathrm{Fe}^{\mathrm{III}}{ }_{0.57}\left(\mathrm{HPO}_{3}\right)_{6}\right] \cdot 1.5 \mathrm{H}_{2} \mathrm{O}^{23} \quad$ and $\mathrm{Fe}^{\mathrm{II}}{ }_{2.08} \mathrm{Fe}^{\mathrm{III}}{ }_{0.42}\left(\mathrm{H}_{2} \mathrm{O}\right)_{2}\left(\mathrm{HPO}_{3}\right)_{1.58}\left(\mathrm{PO}_{4}\right)_{0.42} \mathrm{~F}^{25}$ and three examples of mixed-valent iron organically templated phosphites, $\left(\mathrm{NH}_{4}\right)\left[\mathrm{Fe}_{2}{ }^{\mathrm{II}} \mathrm{Fe}^{\mathrm{III}}\left(\mathrm{HPO}_{3}\right)_{4}\right],{ }^{26}\left(\mathrm{C}_{4} \mathrm{H}_{12} \mathrm{~N}_{2}\right)\left[\mathrm{Fe}^{\mathrm{II}} \mathrm{Fe}^{\mathrm{III}}\left(\mathrm{HPO}_{3}\right)_{2} \mathrm{~F}_{3}\right]^{27}$ and
$\left(\mathrm{C}_{4} \mathrm{~N}_{2} \mathrm{H}_{12}\right)\left[\mathrm{Fe}_{0.86}^{\mathrm{II}} \mathrm{Fe}^{\mathrm{III}}{ }_{1.14}\left(\mathrm{HPO}_{3}\right)_{1.39}\left(\mathrm{HPO}_{4}\right)_{0.47}\left(\mathrm{PO}_{4}\right)_{0.14} \mathrm{~F}_{3}\right] .{ }^{28}$

In addition, many times the design and synthesis of magnetic materials pass through the study of replacing the transition metals. For example, cobalt-iron bimetallic molecular magnets based on cyano-bridged coordination polymers ${ }^{29}$ (Prussian Blue analogues) and oxalate-bridged complexes, ${ }^{30}$ have been of great ${ }_{65}$ interest due to their functional magnetic properties, such as photoinduced magnetism, ${ }^{31}$ anisotropic photoinduced magnetism in thin films, ${ }^{32}$ and a charge-transfer-induced spin transition. ${ }^{33}$

In this work, in order to satisfy the host guest charge matching principle, ${ }^{10}$ the choice of the chain-type tetramine N,N'-Bis(270 aminoethyl)-1,3-propanediamine (baepn $=\mathrm{C}_{7} \mathrm{~N}_{4} \mathrm{H}_{20}$ ) as the structure directing agent, which may arise highly charged, is accompanied by introducing $\mathrm{F}^{-}$anion which also plays the role of template stabilizing the construction of the resulting network. While this molecule has been used for the construction of some 75 transition metal coordination polymers, ${ }^{34}$ wherein the organic ligand is coordinated by its four nitrogen atoms to the equatorial plane of the metallic polyhedra, we ignore its use for the synthesis of zeotypes or related compounds.

In this paper, we report on the hydrothermal synthesis, crystal 80 structure determination, as well as the thermal, spectroscopic behaviour and magnetic properties of $\left(\mathrm{H}_{4} \text { baepn }\right)_{0.5}\left[\mathrm{Fe}^{\mathrm{III}}{ }_{2.3} \mathrm{Fe}^{\mathrm{II}}{ }_{1.7}\left(\mathrm{H}_{2} \mathrm{O}\right)_{2}\left(\mathrm{HPO}_{3}\right)_{4-(\mathrm{x}+\mathrm{y})}\left(\mathrm{HPO}_{4}\right)_{\mathrm{x}}\left(\mathrm{PO}_{4}\right)_{\mathrm{y}} \mathrm{F}_{4}\right]$ $(\mathrm{x} \simeq 0.13, \mathrm{y} \simeq 0.3) 1$. The partially replacement of $\mathrm{Fe}(\mathrm{II})$ by $\mathrm{Co}(\mathrm{II})$ has given rise to $\left(\mathrm{H}_{4} \text { baepn }\right)_{0.5}\left[\mathrm{Fe}^{\mathrm{III}}{ }_{2.0} \mathrm{Fe}^{\mathrm{II}}{ }_{0.71} \mathrm{Co}^{\mathrm{II}}{ }_{1.29}\left(\mathrm{H}_{2} \mathrm{O}\right)_{2}\left(\mathrm{HPO}_{3}\right)_{4}\right.$ $\left.{ }_{85}{ }_{\mathrm{x}}\left(\mathrm{HPO}_{4}\right)_{\mathrm{x}} \mathrm{F}_{4}\right] \quad(\mathrm{x} \simeq 0.38) \quad \mathbf{2}$ as single crystals and $\left(\mathrm{H}_{4} \text { baepn }\right)_{0.5}\left[\mathrm{Fe}^{\mathrm{III}}{ }_{2.0} \mathrm{Fe}^{\mathrm{II}}{ }_{0.62} \mathrm{Co}_{1.38}^{\mathrm{II}}\left(\mathrm{H}_{2} \mathrm{O}\right)_{2}\left(\mathrm{HPO}_{3}\right)_{4-\mathrm{x}}\left(\mathrm{HPO}_{4}\right)_{\mathrm{x}} \mathrm{F}_{4}\right]$ $(x \simeq 0.38) 3$ as polycrystalline sample. The structural influence of the introduction of $\mathrm{Co}$ (II) ions by means of the analysis of the crystal structures of $\mathbf{1}$ and $\mathbf{2}$ will be discussed. Moreover, the 90 differences in the magnetic properties between $\mathbf{1}$ and the phase with the major content of cobalt achieved, $\mathbf{3}$, will be analyzed.

\section{Experimental section}

\section{Synthesis and characterization}

Compounds 1, 2 and 3 were obtained as pure phases from 95 different reactions. The synthetic procedure consists of dissolving a mixture of $\mathrm{H}_{3} \mathrm{PO}_{3}(7.5 \mathrm{mmol})$ and the metal salts $\left(\mathrm{FeCl}_{3}, 0.45\right.$ mmol for 1; $\mathrm{FeCl}_{3}: \mathrm{CoCl}_{2}, 0.3: 0.3 \mathrm{mmol}$ for 2 and $\mathrm{FeCl}_{3}: \mathrm{CoCl}_{2}$, 0.525:0.525 $\mathrm{mmol}$ for 3 ) in $30 \mathrm{ml}$ of distilled water. Then, $0.5 \mathrm{ml}$ $(13.9 \mathrm{mmol})$ of HF was added to the resulting solution and finally 100 the $\mathrm{pH}$ was increased up to approximately 2.5 by adding dropwise the organic molecule $\mathrm{N}, \mathrm{N}^{\prime}$-Bis(2-aminoethyl)-1,3propanediamine $\left(\mathrm{C}_{7} \mathrm{~N}_{4} \mathrm{H}_{20}\right)$. The reaction mixtures were sealed in a PTFE-lined stainless steel pressure vessel (fill factor 65\%) and heated for 4 days at $170{ }^{\circ} \mathrm{C}$. After the reaction, black tabular 105 single crystals of $\mathbf{1}$ and purplish products as prismatic single crystals and as powder for $\mathbf{2}$ and $\mathbf{3}$ respectively were obtained. The yield for the three compounds is around $50-60 \%$ (based on the reagent iron). The existence of $\mathrm{Co}$ in the samples was confirmed by XRF as preliminary characterization test.

110 After many attempts, compound 2 represents the phase as single crystal with the higher cobalt content achieved. The obtaining of compound $\mathbf{3}$ reveals that it is possible to achieve higher cobalt contents as powder sample. However any attempt to increase the cobalt content of the $\mathrm{FeCl}_{3}: \mathrm{CoCl}_{2}$ molar ratio 


\title{
Cite this: DOI: $10.1039 / \mathrm{c0xx00000x}$
}

\author{
www.rsc.org/xxxxxx
}

ARTICLE TYPE

provoked the crystallization of the purely inorganic fluorinated $\mathrm{Co}(\mathrm{II})$ phosphite $\mathrm{Co}_{2.5}\left(\mathrm{H}_{2} \mathrm{O}\right)_{2}\left(\mathrm{HPO}_{3}\right)_{2} \mathrm{~F}^{25}$ as impurity.

Several attempts to replace the organic template by mobile cations such as $\mathrm{Li}^{+}$or $\mathrm{Na}^{+}$were made in order to obtain a new ${ }_{5}$ phase with conductive properties. However, hydroxides used as lithium and/or sodium sources seemed to act merely basifying the dissolution and causing the decomposition of the organic molecule in such a way that iron(III) phosphite $\left(\mathrm{C}_{4} \mathrm{~N}_{3} \mathrm{H}_{14}\right)\left[\mathrm{Fe}_{3}\left(\mathrm{HPO}_{3}\right)_{4} \mathrm{~F}_{2}\left(\mathrm{H}_{2} \mathrm{O}\right)_{2}\right]^{35}$ crystallizes.

10 The metal ion and phosphorous contents were confirmed by inductively coupled plasma quadrupole mass spectrometry (ICPQ-MS) analysis, performed with a Thermo Scientific XSERIES 2 spectrometer. The amount of the fluoride anion was calculated by using a selective electrode and the amounts of $\mathrm{C}, \mathrm{N}$ and $\mathrm{H}$ by ${ }_{15}$ elemental analysis. ( $\mathrm{H}_{4}$ baepn $)_{0.5}\left[\mathrm{Fe}^{\mathrm{III}}{ }_{2.3} \mathrm{Fe}^{\mathrm{II}}{ }_{1.7}\left(\mathrm{H}_{2} \mathrm{O}\right)_{2}\left(\mathrm{HPO}_{3}\right)_{4}\right.$ $\left.(\mathrm{x}+\mathrm{y})\left(\mathrm{HPO}_{4}\right)_{\mathrm{x}}\left(\mathrm{PO}_{4}\right)_{\mathrm{y}} \mathrm{F}_{4}\right] \quad(\mathrm{x} \simeq 0.13, \mathrm{y} \simeq 0.3) \quad$ 1. Calculated $(\%): \mathrm{Fe}$, 30.02 ; P, 16.65; F, 10.21; C, 5.65; N, 3.77; H, 2.67. Found (\%): Fe, 29.7(4); P, 16.4(3); F, 9.8(3); C 5.4(4); N, 3.5(2); H, 2.6(1). $\left(\mathrm{H}_{4} \text { baepn }\right)_{0.5}\left[\mathrm{Fe}^{\text {III }}{ }_{2.0} \mathrm{Fe}^{\text {II }}{ }_{0.71} \mathrm{Co}^{\text {II }}{ }_{1.29}\left(\mathrm{H}_{2} \mathrm{O}\right)_{2}\left(\mathrm{HPO}_{3}\right)_{4-\mathrm{x}}\left(\mathrm{HPO}_{4}\right)_{\mathrm{x}} \mathrm{F}_{4}\right]$

$20(\mathrm{x} \simeq 0.38)$ 2. Calculated (\%): Fe, 20.25; Co, 10.17; P, 16.57; F, 10.17; C, 5.62; N, 3.75; H, 2.70. Found (\%): Fe, 20.3(3); Co, 10.2(3); P, 16.8(3); F, 10.0(3); C 5.7(4); N, 3.6(2); H, 2.7(1). $\left(\mathrm{H}_{4} \text { baepn }\right)_{0.5}\left[\mathrm{Fe}^{\text {III }}{ }_{2.0} \mathrm{Fe}^{\mathrm{II}}{ }_{0.62} \mathrm{Co}^{\mathrm{II}}{ }_{1.38}\left(\mathrm{H}_{2} \mathrm{O}\right)_{2}\left(\mathrm{HPO}_{3}\right)_{4-\mathrm{x}}\left(\mathrm{HPO}_{4}\right)_{\mathrm{x}} \mathrm{F}_{4}\right]$ $(\mathrm{x} \simeq 0.38)$ 3. Calculated $(\%)$ : Fe, 19.57; Co, 10.88; P, 16.57; F, ${ }_{25}$ 10.16; C, 5.62; N, 3.75; H, 2.70. Found (\%): Fe, 19.6(3); Co, 10.9(3); P, 16.7(3); F, 10.3(3); C 5.5(4); N, 3.8(2); H, 2.7(1).

The densities of the three phases were measured by flotation using a mixture of $\mathrm{CH}_{2} \mathrm{I}_{2}$ and $\mathrm{CHCl}_{3}$, being 2.50(3) g. $\mathrm{cm}^{-3}$ for $\mathbf{1}$, 2.51(3) g.cm $\mathrm{cm}^{-3}$ for $\mathbf{2}$, and 2.51(2) g.cm $\mathrm{cm}^{-3}$ for $\mathbf{3}$

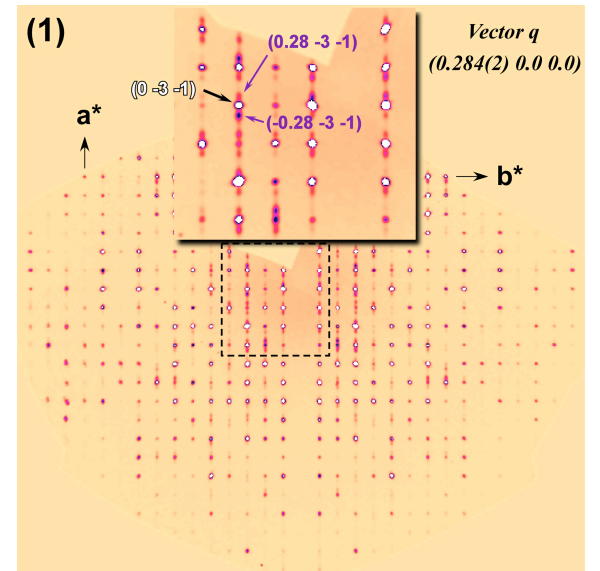

\section{${ }_{30}$ Single crystal $X$-ray diffraction study}

High quality single crystals for $\mathbf{1}$ and $\mathbf{2}$ were selected under a polarizing microscope and mounted on a glass fiber. Intensity data were collected at $100 \mathrm{~K}$ on an AGILENT SUPERNOVA diffractometer using a CCD (Eos) detector. Data frames were 35 processed (unit cell determination, intensity data integration, correction for Lorentz and polarization effects, ${ }^{36}$ and analytical absorption correction $^{37}$ taking into account the size and shape of the crystals) using the corresponding diffractometer software package. $^{38}$

40 Reciprocal space analysis of compound $\mathbf{1}$ revealed the presence of weak reflections not arbitrary distributed but equidistant from the main reflections along the $\mathrm{a}^{*}$ axis (Fig. S1). These additional less intense peaks, referred to as satellite reflections, are the result of the existence of a structural 45 modulation periodic in nature, which describes a long-range order. The modulation wavevector which describe the first-order satellites with respect to the main reflections is $q=0.284(2) \mathrm{a}^{*}$ (Fig. 1), allowing the indexing of the diffraction pattern with four indices hklm. However, the low intensity of the satellite 50 reflections together with the existence of diffuse scattering (Fig. S2) hinder the superspace group and the atomic modulation functions determination in order to describe the incommensurately modulated superstructure. While satellite reflections mark an incommensurate long-range order, diffuse 55 scattering processes suggest the existence of a certain disorder, dynamic or static, that breaks slightly the crystallographic order. On the other hand, compound $\mathbf{2}$ shows neither satellites nor diffuse scattering (Fig. 1 and Fig. S2).

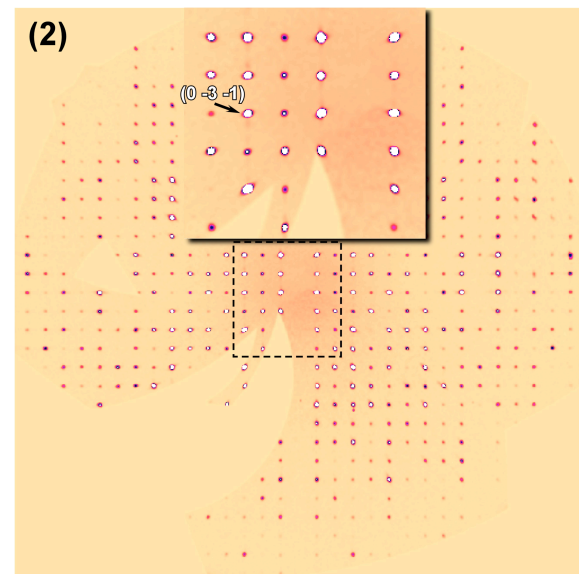

Fig. 1 Experimental images of the hk-1 layers of the diffraction patterns for 1 and $\mathbf{2}$ reconstructed using the CrysAlisPro software package. ${ }^{38}$

Therefore, we focused on the average structures, ignoring the satellite reflections. The structures were solved by direct methods, SHELXS 97 computer program, ${ }^{39}$ in the monoclinic space group $\mathrm{P} 2{ }_{1} / \mathrm{c}$, and then refined by the full matrix least${ }_{65}$ squares procedure based on $\mathrm{F}^{2}$, using the SHELXL 97 computer program $^{40}$ belonging to the WINGX software package. ${ }^{41}$ This procedure allowed us to find the positions of the iron and phosphorous atoms, and all the other non-hydrogen atoms (F, O, $\mathrm{C}$ and $\mathrm{N}$ ) were placed from subsequent Fourier-difference map 70 calculations.

For both compounds, half organic molecule is located in the asymmetric unit and a symmetry centre generates the other half causing a symmetry disorder of the C(4) atom with an occupation factor of 0.5 , giving rise to the existence of two conformers (A 
and B). Due to this peculiarity, an hydrogen disorder system was modeled for their parent $\mathrm{C}(3)$ atom, which is bonded to $\mathrm{C}(4)$ (Fig. S3). Isotropic thermal displacements were used for carbon and nitrogen atoms.

From subsequent Fourier-difference map calculations, electron-densities exceeding $1.0 \mathrm{e}^{-} \cdot \AA^{-3}$ and too long P-Q distances for apical hydrogen were observed near $\mathrm{P}(1), \mathrm{P}(2)$ and $\mathrm{P}(3)$. The presence of both phosphite and phosphate groups was considered in these phosphorus sites. The existence of hydrogenphosphate 10 groups, $\left(\mathrm{HPO}_{4}\right)^{2-}$, were deduced from electroneutrality requirements. Hydrogen and oxygen atoms implicated in the anionic phosphorous groups replacements were treated as disordered ones with complementary occupation factors. In order to model correctly the disorder systems, P-H (1.30(1) Å) and P-O

15 (1.50(1) $\AA$ ) bonds were restrained to the ideal values. Moreover, in order to maintain the geometry of the $\left(\mathrm{HPO}_{3}\right)^{2-}$ groups, the three distances of the apical hydrogen atoms to their corresponding oxygen atoms forming the pseudotetrahedra base were refined as a variable.

20 For compound 2, $\mathrm{Co}^{2+}$ ions should be located in the $\mathrm{M}(3)$ and $\mathrm{M}(4)$ sites given the metal-ligand distances. The best fit provides a full occupation of the $\mathrm{M}(4)$ position and an occupation factor of 0.3 (1) for $\mathrm{M}(3)$ in good agreement with the chemical analysis.

For the final refinement of compounds $\mathbf{1}$ and $\mathbf{2}$, the hydrogen 25 atoms related to the coordinated water molecules were first located and placed in geometrically ideal positions $(\mathrm{O}-\mathrm{H}: 0.82(1)$ $\AA$; H-H: $1.35(2) \AA$ ) and refined using the riding mode. Anisotropic thermal parameters were used for all the atoms belonging to the inorganic framework except for the hydrogen 30 atoms and, the oxygen atoms implicated in the $\mathrm{P}(1), \mathrm{P}(2)$ and $\mathrm{P}(3)$ disorder systems.

After the refinement of both phases, two residual density maxima of approximately $\pm 3 \mathrm{e}^{-} \cdot \AA^{-3}$ are located near $\mathrm{N}(2)$. In compound 2 , there are also another five peaks located along the 35 chain suggesting positional disorder of the organic template. Furthermore, in compound $\mathbf{1}$ two electron density peaks of \pm 3.4 and $3.2 \mathrm{e}^{-} \cdot \AA^{-3}$ are found at the equatorial plane of the iron $\left[\mathrm{M}(4) \mathrm{O}_{2} \mathrm{~F}_{2}\left(\mathrm{H}_{2} \mathrm{O}\right)_{2}\right]$ octahedron as well as a peak of around $\pm 2.3 \mathrm{e}^{-}$ $\cdot \AA^{-3}$ at $1 \AA$ from the $\mathrm{P}(4)$ atom. Such peaks located in the 40 inorganic skeleton of $\mathbf{1}$ are also located in compound $\mathbf{2}$ but with significantly lower density values, around $\pm 1 \mathrm{e}^{-} \cdot \AA^{-3}$. In case of compound 1 , such anomalies are caused by the average structure resolution neglecting the satellite intensity due to the periodic character of the modulation

${ }_{45}$ Details of crystal data, data measurement and reduction, structure solution and refinement of the phases $\mathbf{1}$ and $\mathbf{2}$ are reported in Table 1. The selected bond distances and angles are reported in ESI, Tables S1 and S2. Structure drawings were made using the ATOMS $6.2,{ }^{42}$ VESTA $3.1 .7^{42}$ and TOPOS 4.0 programs. ${ }^{43}$

\section{${ }_{50}$ Powder X-ray diffraction}

X-ray powder diffraction for qualitative phase analysis of phase 3 using the Rietveld method with the FullProf program ${ }^{44}$ was recorded using a Bruker D8 Advance Vario powder diffractometer equipped with a $\mathrm{Cu}$ tube, $\mathrm{Ge}(111)$ incident beam 55 monochromator $\left(\mathrm{Cu}-\mathrm{K}_{\mathrm{a} 1}=1.5406 \AA\right)$, and a Sol-X energy dispersive detector. The sample was mounted on a zero background silicon wafer embedded in a generic sample holder. Data were collected from 8 to $80^{\circ} 2 \theta$ (step size $=0.02^{\circ}$ and time per step $=90 \mathrm{~s}$ ) at RT. Fixed divergence and antiscattering slit ${ }_{60}$ giving a constant volume of sample illumination were used.

For the Rietveld refinement of $\mathbf{3}$, obtained as powdered sample, the structural model of $\mathbf{2}$ was used. The cobalt content was fixed to the amount calculated by the ICP-Q-MS analysis. The fitting of the profile parameters followed by refinement of ${ }_{65}$ the atomic coordinates and the atomic displacement parameters of the inorganic skeleton was performed. The organic template was not refined. Four different isotropic displacement parameters were refined: one for the iron and cobalt atoms, and the remainder for de phosphorous, oxygen and fluorine atoms. Some 70 soft constraints were included to have a chemically correct structural model.

Table 1 Crystallographic data and structure refinement parameters for phases 1 and 2 obtained by single crystal X-ray diffraction

\begin{tabular}{|c|c|c|}
\hline Phase & 1 & 2 \\
\hline $\begin{array}{l}\text { Molecular weight } \\
\left(\mathrm{gmol}^{-1}\right)\end{array}$ & 744.05 & 747.53 \\
\hline Space group & \multicolumn{2}{|l|}{$\mathrm{P} 22_{1} / \mathrm{c}$} \\
\hline a, b, c $(\AA)$ & $\begin{array}{l}13.6808(4) \\
12.6340(2) \\
12.7830(3) \\
\end{array}$ & $\begin{array}{l}13.6823(4) \\
12.6063(3) \\
12.7535(4) \\
\end{array}$ \\
\hline$\beta\left(^{\circ}\right)$ & $116.983(4)$ & $116.988(4)$ \\
\hline $\mathrm{V}\left(\AA^{3}\right), \mathrm{Z}$ & 1968.94(8), 4 & 1960.21(10), 4 \\
\hline$\rho_{\mathrm{obs}}, \rho_{\text {calc }}\left(\mathrm{gcm}^{-3}\right)$ & $2.50(3), 2.51$ & $2.51(3), 2.53$ \\
\hline Cristal size $(\mathrm{mm})$ & $0.231 \times 0.094 \times 0.052$ & $0.224 \times 0.066 \times 0.061$ \\
\hline $\mathrm{F}(000)$ & 1482 & 1480 \\
\hline $\begin{array}{l}\text { Diffractometer / } \\
\text { Temperature (K) }\end{array}$ & \multicolumn{2}{|c|}{$\begin{array}{l}\text { AGILENT SUPERNOVA (omega scan mode) } \\
100(2)\end{array}$} \\
\hline $\begin{array}{l}\mu\left(\mathrm{mm}^{-1}\right) \\
\text { Tmin./Tmáx. }\end{array}$ & $3.325,0.694 / 0.865$ & $3.499,0.757 / 0.839$ \\
\hline Radiation $(\AA)$ & \multicolumn{2}{|l|}{$\lambda(\operatorname{Mo~K} \alpha)=0.71073$} \\
\hline $\begin{array}{l}\text { Limiting indices } \\
\mathrm{h}, \mathrm{k}, 1\end{array}$ & $\begin{array}{l}-16 \leq h \leq 15 \\
k \pm 15 \\
l \pm 15\end{array}$ & $\begin{array}{l}h \pm 16 \\
k \pm 15 \\
l \pm 15\end{array}$ \\
\hline $\begin{array}{l}\text { Theta range }\left({ }^{\circ}\right) \\
\text { Completeness }(\%)\end{array}$ & $1.67-25.68,99.8$ & $1.67-25.68,99.3$ \\
\hline $\begin{array}{l}\text { N. reflections } \\
\text { (measured) } \\
\text { (independents) } \\
\text { (observed) } \\
\end{array}$ & $13887 / 3726 / 3670$ & $13695 / 3700 / 3537$ \\
\hline $\mathrm{R}$ (int) / R(sigma) & $0.0189 / 0.016$ & $0.0247 / 0.0212$ \\
\hline $\begin{array}{l}\text { Parameters } \\
\text { Restrictions }\end{array}$ & 314 / 61 & $317 / 51$ \\
\hline $\mathrm{R}[\mathrm{I}>2 \sigma(\mathrm{I})]$ & $\begin{array}{l}\mathrm{R} 1=0.0867 \\
\mathrm{wR} 2=0.2067\end{array}$ & $\begin{array}{l}\mathrm{R} 1=0.0658 \\
\mathrm{wR} 2=0.1384\end{array}$ \\
\hline $\mathrm{R}$ [all data] & $\begin{array}{l}\mathrm{R} 1=0.0873 \\
\mathrm{wR} 2=0.2069\end{array}$ & $\begin{array}{l}\mathrm{R} 1=0.0676 \\
\mathrm{wR} 2=0.1391\end{array}$ \\
\hline Weight factor & $\begin{array}{l}x=0.0577 \\
y=95.4386\end{array}$ & $\begin{array}{l}x=0.0072 \\
y=62.0640\end{array}$ \\
\hline G. O. F & 1.123 & 1.129 \\
\hline $\begin{array}{l}\text { Max. and Min. } \\
\text { e. density }\left(e \AA^{-3}\right)\end{array}$ & $3.423,-1.658$ & $3.08,-1.619$ \\
\hline
\end{tabular}

Finally, all parameters (profile and structural) were refined 75 simultaneously to obtain correct e.s.d.'s, obtaining a good agreement between the experimental and the calculated diffractogram (Fig. S4). So, the proposed chemical formula for 3 is $\left(\mathrm{H}_{4} \text { baepn }\right)_{0.5}\left[\mathrm{Fe}^{\mathrm{III}}{ }_{2.0} \mathrm{Fe}^{\mathrm{II}}{ }_{0.62} \mathrm{Co}^{\mathrm{II}}{ }_{1.38}\left(\mathrm{H}_{2} \mathrm{O}\right)_{2}\left(\mathrm{HPO}_{3}\right)_{4-\mathrm{x}}\left(\mathrm{HPO}_{4}\right)_{\mathrm{x}} \mathrm{F}_{4}\right]$ 
( $x \simeq 0.38$ ), confirming the isostructurality between the three phases. (See Tables S3 to S5 for atomic coordinates and bond distances and angles of the Rietveld refinement of $\mathbf{3}$ ).

In addition, the pattern matching analysis of the diffraction 5 patterns of the three compounds confirming the purity of the samples is given as Supplementary Material (Fig. S5).

\section{Physicochemical characterization techniques}

Thermogravimetric analyses were performed on a SDT 2960 simultaneous DSC-TGA TA instrument for $\mathbf{1}$ and on a Netzsch ${ }_{10}$ STA $449 \mathrm{C}$ one for 2 and 3 . Alumina crucibles containing around $20 \mathrm{mg}$ of every sample were heated in air at a rate of $5{ }^{\circ} \mathrm{C} / \mathrm{min}$ from room temperature to $800{ }^{\circ} \mathrm{C}$. Temperature dependence $\mathrm{X}$ ray diffraction experiments for $\mathbf{1}$ and $\mathbf{3}$ were carried out in air with a Bruker D8 Advance diffractometer $(\mathrm{Cu} \mathrm{K \alpha}$ radiation) 15 equipped with, a variable-temperature stage (HTK2000), a Pt sample heater and a Vantec high-speed one dimensional detector with six degrees of angular aperture. The powder patterns were recorded in the $8 \leq 2 \theta \leq 38^{\circ}$ range (step size $=0.033^{\circ}$ and time per step $=0.4 \mathrm{~s}$ ) at intervals of $15^{\circ} \mathrm{C}$, increasing the temperature at 10 ${ }_{20}^{\circ} \mathrm{Cmin}^{-1}$ from room temperature to $810^{\circ} \mathrm{C}$. The IR spectra $(\mathrm{KBr}$ pellets) were obtained with a JASCO FT/IR-6100 spectrophotometer in the $400-4000 \mathrm{~cm}^{-1}$ range. Diffuse reflectance spectra were registered at room temperature on a Varian Cary 5000 spectrophotometer in the 200-2500 nm range. ${ }_{25} \mathrm{X}$-ray photoelectron spectra for $\mathbf{1}, \mathbf{2}$ and $\mathbf{3}$ were acquired with a SPECS (Berlin, Germany) system equipped with a Phoibos 150 1D-DLD analyzer and monochromatic AlK $\alpha$ radiation (1486.6 $\mathrm{eV}, 300 \mathrm{~W}, 13 \mathrm{kV}$ ), with a multi-channel detector. Spectra were recorded in the constant pass energy mode at $80 \mathrm{eV}$ for survey 30 spectra and $30 \mathrm{eV}$ for high resolution spectra, with an electron take-off angle of $90^{\circ}$. The spectrometer was previously calibrated using the $\mathrm{Ag} 3 \mathrm{~d}_{5 / 2}$ line at $368.28 \mathrm{eV}$. The binding energy of the adventitious carbon (C1s) was set at $284.6 \mathrm{eV}$ to correct sample charging. The spectra were fitted with the CasaXPS 2.3.16
35 software, which models the Gauss-Lorentzian contributions, after background subtraction (Shirley). Mössbauer spectra of 1, 2 and 3 were obtained using a constant-acceleration Mössbauer spectrometer with a ${ }^{57} \mathrm{Co} / \mathrm{Rh}$ source. Velocity calibration was done using a metallic Fe foil, and the Mössbauer spectral 40 parameters are given relative to this standard at room temperature. The Mössbauer spectra were fitted with the NORMOS program. ${ }^{45}$ Magnetic measurements on the powdered samples were performed in the temperature range $2.0-300 \mathrm{~K}$ for 1 and 3, at $0.05,0.2$ and $1 \mathrm{~T}$ using a MPMS-7T SQUID 45 magnetometer and a PPMS-system both from Quantum Design. Heat capacity measurements for $\mathbf{1}$ and $\mathbf{3}$ were carried out by a standard two- $\tau$ relaxation method, using a PPMS-system, with magnetic fields up to $9 \mathrm{~T}$ and temperatures down to $2 \mathrm{~K}$.

\section{Results and discussion}

\section{${ }_{50}$ Structure description}

The asymmetric unit of $\mathbf{1}$ contains 35 non-hydrogen atoms, 29 of which belong to the host framework (four Fe, four $\mathrm{P}$, four $\mathrm{F}$ and seventeen $\mathrm{O}$ ) and the remaining 6 to the guest species (two $\mathrm{N}$ and four $\mathrm{C})$. Three of the oxygen atoms $\left(\mathrm{O}^{\prime}, \mathrm{O}^{\prime}\right.$ and $\left.\mathrm{O} 3^{\prime}\right)$ present ${ }_{55}$ partial occupation as they belong to the hydrogenphosphate or phosphate groups which partially replace the phosphite units. All of crystallographically independent atoms occupy general positions except the $\mathrm{C}(4)$ atom which present half site occupancy in order to generate the whole organic template. In 2 a total ${ }_{60}$ replacement of $\mathrm{Fe}(4)$ by $\mathrm{Co}(4)$ and a partial substitution of $\mathrm{Fe}(3)$ by $\mathrm{Co}(3)$ occurs in the $\mathrm{M}(3)$ and $\mathrm{M}(4)$ positions (Fig. S6).

The average structure of compound $\mathbf{1}$ is constituted by a threedimensional lattice formed by inorganic layers of iron (III) and iron (II) octahedra joined by the $\mathrm{P}(1)$ and $\mathrm{P}(2)$ phosphite groups ${ }_{65}$ (Fig. 2a).

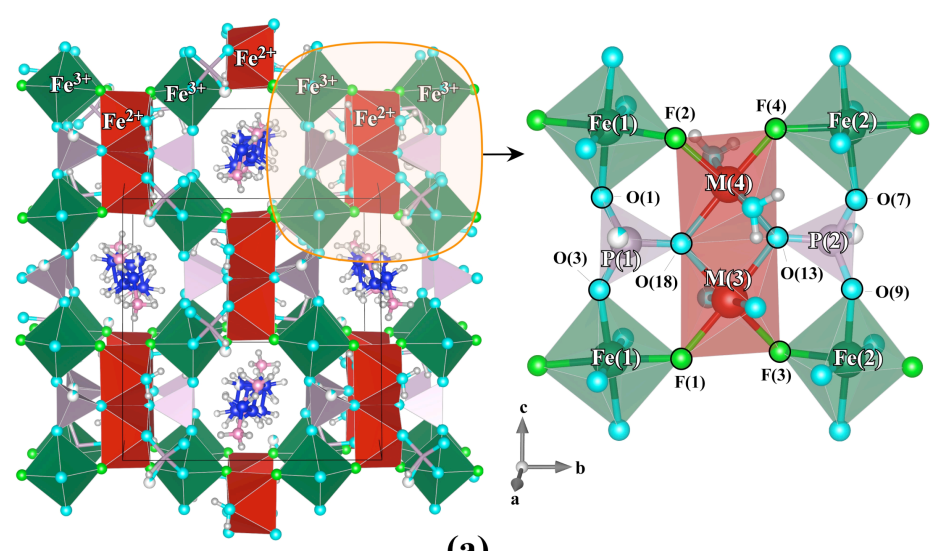

(a)

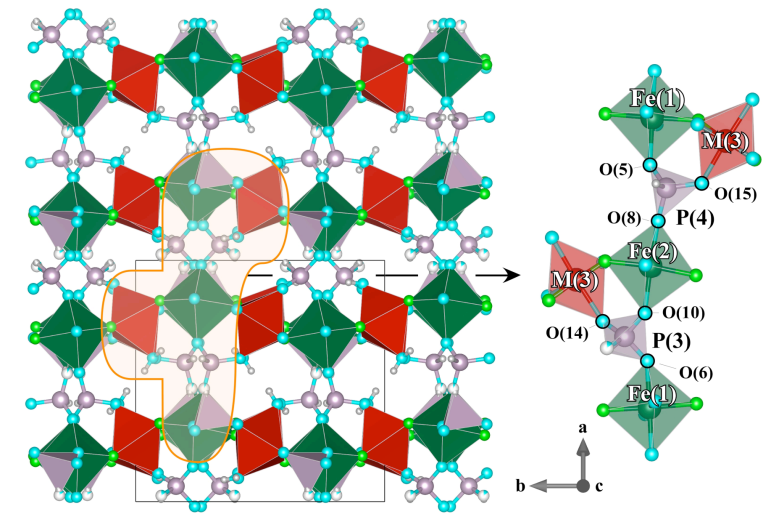

(b)

Fig. 2 a) Polyhedral representation of the 3D crystal structure of 1 viewed along the [100] direction. The shaded area shows a zoomed cut of the connectivity inside the inorganic layers. b) Layers stacking by $\mathrm{P}(3)$ and $\mathrm{P}(4)$ bridging units.

These layers link between them through the $\mathrm{P}(3)$ and $\mathrm{P}(4)$ 70 bridging $\mathrm{HPO}_{3}$ units (Fig. 2b). The iron (III) octahedra $\mathrm{Fe}(1) \mathrm{O}_{4} \mathrm{~F}_{2}$ and $\mathrm{Fe}(2) \mathrm{O}_{4} \mathrm{~F}_{2}$ share oxygen vertices of the phosphorous pseudotetrahedra giving rise to [001] chains. These chains are joined along the [010] direction, through the iron(II) octahedra dimers $\mathrm{M}(3) \mathrm{O}_{4} \mathrm{~F}_{2}$ and $\mathrm{M}(4) \mathrm{O}_{2}\left(\mathrm{H}_{2} \mathrm{O}\right)_{2} \mathrm{~F}_{2}$, which share the $\mathrm{O}(18)-$
${ }_{75} \mathrm{O}(13)$ edges, leading to the layers, which have eight-membered structural windows (Fig. 2a). These anionic layers stack along the [100] direction generating the open channels along the same direction, where the protonated templates are placed longitudinally (Fig. 2a and 3a), neutralizing the negative charge 80 excess and stabilizing the inorganic building through hydrogen 
bonds (Fig. 3b).

The two types of iron (III) octahedra chains, formed by the $\left[\mathrm{Fe}(1) \mathrm{O}_{4} \mathrm{~F}_{2}\right]$ octahedra linked together by the $\mathrm{P}(1)$ polyhedra and the $\left[\mathrm{Fe}(2) \mathrm{O}_{4} \mathrm{~F}_{2}\right]$ octahedra linked by the $\mathrm{P}(2)$ polyhedra, alternate 5 in the [010] direction. Notice that the direction of the $\mathrm{P}(1)-\mathrm{H}(1)$ and $\mathrm{P}(2)-\mathrm{H}(2)$ bonds are opposite. Moreover, it can be observed that the octahedra are linked between them through fluorine atoms along the $b$ axis giving rise to an infinite $-\mathrm{Fe}^{3+}-\mathrm{F}-\mathrm{Fe}^{2+}-\mathrm{F}-$ linkage (Fig. 2a). The $\mathrm{M}(4) \mathrm{O}_{2}\left(\mathrm{H}_{2} \mathrm{O}\right)_{2} \mathrm{~F}_{2}$ octahedron is not 10 involved in the layers stacking because of the two water molecules are coordinated at the apical positions roughly parallel to the stacking direction.

In the $\left[\mathrm{Fe}(1) \mathrm{O}_{4} \mathrm{~F}_{2}\right]$ and $\left[\mathrm{Fe}(2) \mathrm{O}_{4} \mathrm{~F}_{2}\right]$ polyhedra the $\mathrm{Fe}-\mathrm{O}$ bond lengths (1.938(8)-2.011(7) $\AA$ for 1 and 1.935(6)-2.000(6) $\AA$ for 2) 15 as well as the Fe-F distances (1.929(7)-1.983(7) $\AA$ for $\mathbf{1}$ and 1.929(6)-1.993(4) $\AA$ for 2) are in good agreement with 3+ oxidation state for the $\mathrm{Fe}(1)$ and $\mathrm{Fe}(2)$ atoms, based on the bond valence sums (BVS) calculations. ${ }^{46}$ Both polyhedra display eight $\mathrm{O}-\mathrm{Fe}-\mathrm{F}$ and four $\mathrm{O}-\mathrm{Fe}-\mathrm{O}$ cis angles, and two O-Fe-O and one $\mathrm{F}-$ ${ }_{20} \mathrm{Fe}-\mathrm{F}$ trans angles. However, in the $\left[\mathrm{M}(3) \mathrm{O}_{4} \mathrm{~F}_{2}\right]$ and $\left[\mathrm{M}(4) \mathrm{O}_{2}\left(\mathrm{H}_{2} \mathrm{O}\right)_{2} \mathrm{~F}_{2}\right]$ octahedra, $\mathrm{M}-\mathrm{O}$ bond lengths span from 2.060(6) to 2.274(8) $\AA$ for $\mathbf{1}$ and from 2.056(4) to 2.216(6) $\AA$ for 2 , and the M-F distances are in the ranges 1.996(6)-2.148(7) $\AA$ for 1 and 1.994(5)-2.125(5) $\AA$ for 2. In this case, the $\mathrm{M}-\mathrm{O} / \mathrm{F}$ 25 distances indicate at first glance that, from the structural point of view, $M(3)$ and $M(4)$ sites are in +2 state. In these polyhedra the fluorine atoms are located in the edges, giving rise to six O-M-F, five O-M-O and one F-M-F cis angles and four O-M-O cis angles, and two O-M-F and one O-M-O trans angles.

30 The $\mathrm{S}\left(\mathrm{O}_{\mathrm{h}}\right)$ values for phases $\mathbf{1}$ and $\mathbf{2}$, calculated by Continuous Symmetry Measure, ${ }^{47}$ show more distorted octahedra for bivalent metals $(M(3)$ and $M(4))$, however, they represent very slight distortions with regard to the ideal octahedron.

The P-O distances of the $\left(\mathrm{HPO}_{3}\right)^{2-}$ units are in the range 35 1.482(9)-1.544(8) $\AA$ for 1 and 1.493(7)-1.540(6) $\AA$ for 2 , and the $\mathrm{P}-\mathrm{H}$ distances are 1.31(5) $\AA$ and 1.32(5) $\AA$ for $\mathbf{1}$ and $\mathbf{2}$ respectively. The average O-P-O and $\mathrm{H}-\mathrm{P}-\mathrm{O}$ angles are around $112^{\circ}$ and $107^{\circ}$ respectively for both compounds, which are in the usual range for phosphite based compounds. ${ }^{48}$ The terminal $\mathrm{P}(1)$ ${ }_{40} \mathrm{O}\left(1^{\prime}\right)$ bond distances are significantly higher than the rest of the P-O bonds (1.55(4) for 1 and 1.59(3) for 2) which could be in good agreement with the existence of $\left(\mathrm{HPO}_{4}\right)^{2-}$ groups inferred from the electroneutrality of the formula.

The phosphorus atoms make ten $\mathrm{P}-\mathrm{O}-\mathrm{M}(\mathrm{M}=\mathrm{Fe}, \mathrm{Co})$ 45 linkages with minimum and maximum values for the $\mathrm{P}(2)-\mathrm{O}(13)-$ $\mathrm{Fe}(3)$ and $\mathrm{P}(4)-\mathrm{O}(8)-\mathrm{Fe}(2)$ angles $\left[123.3(4)^{\circ}\right.$ and $160.0(7)^{\circ}$ for $\mathbf{1}$ and $123.5(3)^{\circ}$ and $159.1(5)^{\circ}$ for 2 ].

The octahedra sharing vertex display four M-F-M linkages with average angles of $127.5(3)^{\circ}$ for $\mathbf{1}$ and $128.3(2)^{\circ}$ for $\mathbf{2}$. The ${ }_{50} \mathrm{M}(3)$ and $\mathrm{M}(4)$ metals share an edge possessing two M-O-M linkages of around $98^{\circ}$ and $100^{\circ}$ for both phases.

Hydrogen bonding plays an important role linking the tetramine cations to the framework (Fig 3b). The terminal hydrogen-bond donor group, $\mathrm{N}(1)$, interact with the oxygens $\mathrm{O}(6)$ 55 and $\mathrm{O}(17 \mathrm{~W})$ and the fluorine atoms $\mathrm{F}(2)$, and $\mathrm{F}(4)$ while the 'internal' donor group, $\mathrm{N}(2)$, interact with $\mathrm{O}(1), \mathrm{O}(7), \mathrm{F}(1)$ and $\mathrm{F}(3)$. Three $\mathrm{C}-\mathrm{H} \cdots \mathrm{O}$ and one $\mathrm{C}-\mathrm{H} \cdots \mathrm{F}$ contacts are also present in the structures. The complete list of hydrogen bond interactions is shown in Table S6.

In the Cambridge Structural Database (CSD) there are only three structures, based on ionic salts, containing uncomplexed $\mathrm{N}, \mathrm{N}$-Bis(2-aminoethyl)-1,3-propanediamine. In two of them the molecule is a tetracation ${ }^{49}$ and in the other one is a trication, ${ }^{50}$ with gtttttg ( $\mathrm{g}$ indicates gauche and $\mathrm{t}$ trans) and gttggggt ${ }_{65}$ conformations respectively. In the studied compounds, the existence of the symmetry centre forces the splitting of the central carbon (C4) in two positions producing the conformers A and B with conformations not previously seen in the mentioned structures. Given the existence of torsion angles less than $30^{\circ}$ and 70 higher than $90^{\circ}$ (See torsion angles in Tables S1 and S2), the more systematic Klyne-Prelog system ${ }^{51}$ is required to describe them obtaining a ttgaagtt conformation $(\mathrm{a}=$ anticlinal $)$ for the conformers $\mathrm{A}$ and a ttsaastt conformation $(\mathrm{s}=$ synperiplanar) for the conformers B in both compounds.

75 The amount of potential-free volume was estimated by the program PLATON ${ }^{52}$ assuming that the templates could be removed from the channels, being around $20 \%$ of the total volume for phases $\mathbf{1}$ and $\mathbf{2}$. The analysis of the volume occupied by these guest molecules was performed using the TOPOS 4.0 80 program $^{43}$ by means of Voronoi-Dirichlet polyhedra (VDP) ${ }^{53}$ (Fig. 3a) obtaining a $23 \%$ of the crystal volumes. The matching percentage indicates the non-existence of accessible volume.

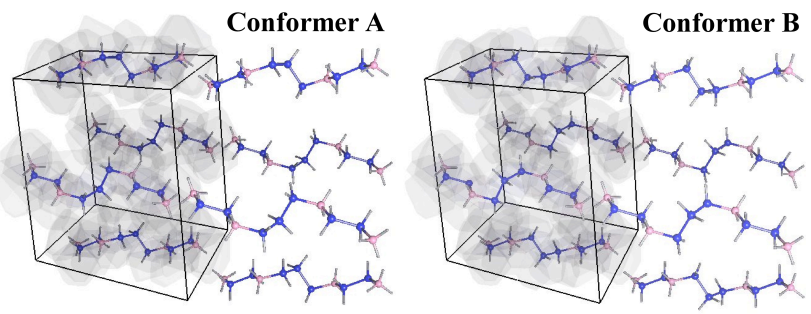

(a)

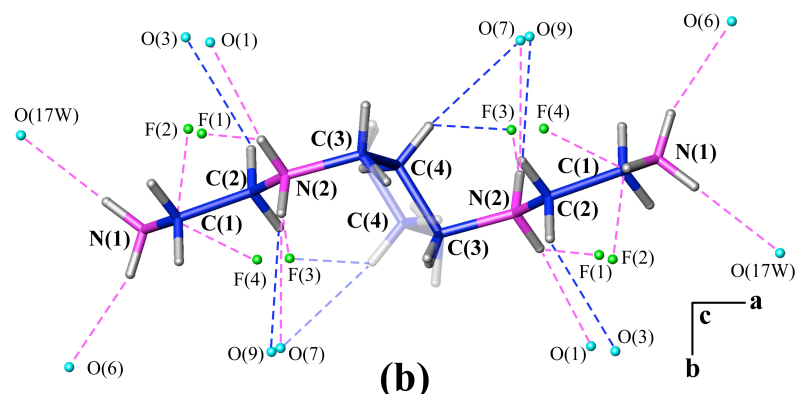

Fig. 3 a) $V D P$ representation of the templates located in the voids of the phase 1. b) Interlayer hydrogen bonds scheme of phase $\mathbf{1}$.

\section{Thermal study}

The TGA curves of 1, 2 and $\mathbf{3}$ show three main weight losses. The results are given in Supporting Information (Fig. S7). The first one $\left(1,80-285^{\circ} \mathrm{C} ; 2\right.$ and $\left.3,80-275^{\circ} \mathrm{C}\right)$ is associated to the 90 release of two coordinated water molecules $(\sim 4.8 \%)$. Afterwards, there are two drops $\left(\mathbf{1}, 285-520^{\circ} \mathrm{C} ; \mathbf{2}\right.$ and $\left.\mathbf{3}, 275^{\circ} \mathrm{C}-540^{\circ} \mathrm{C}\right)$ related to the calcination of the organic molecule $(\sim 11.0 \%)$. This second process is marked by three and two exothermic peaks in the DTA $\left(\mathbf{1}, 285,315\right.$ and $\left.460{ }^{\circ} \mathrm{C}\right)$ and DSC $\left(\mathbf{2}, 269\right.$ and $287^{\circ} \mathrm{C} ; \mathbf{3}, 272$ and ${ }_{95} 292^{\circ} \mathrm{C}$ ) curves, respectively, due to the breakage of C-C and C-N bonds. The third process, which is overlapped with the organic molecule decomposition, is assigned to the elimination of the 
fluoride anions. Two exothermic peaks observed in the DTA (1, 535 and $\left.585^{\circ} \mathrm{C}\right)$ and DSC curves $\left(2\right.$ and 3, 545 and $\left.565{ }^{\circ} \mathrm{C}\right)$ indicate the crystallization of the inorganic residues.

The thermodiffractometry in air of $\mathbf{1}$ and $\mathbf{3}$ reveal that their 5 thermal stability limits are situated at 240 and $255^{\circ} \mathrm{C}$, respectively, in such experimental conditions (Fig. S8). At these temperatures and as a consequence of the elimination of the two coordinated water molecules, the compounds become amorphous and, at $570{ }^{\circ} \mathrm{C}$ the inorganic residues crystallize, in good 10 agreement with the exothermic peaks observed in the DTA and DSC curves. The X-ray powder diffraction patterns of the residues obtained at $800{ }^{\circ} \mathrm{C}$ show the presence of $\mathrm{FePO}_{4}[P D F$ file: 00-050-1635; S.G. P3 21 (152), a= $5.048 \AA$, $\mathrm{c}=11.215 \AA]$ for 1 and $\mathrm{FePO}_{4}$ [PDF file: 01-084-0876; S.G. P3 21 (152), a= $155.027 \AA, \mathrm{c}=11.234 \AA]$ and $\mathrm{Co}_{3} \mathrm{Fe}_{4}\left(\mathrm{PO}_{4}\right)_{6}$ [PDF file: $00-049-1083$; S.G. P-1 (2), $a=7.909 \AA, b=9.289 \AA, c=6.342 \AA, \alpha=108.48^{\circ}, \beta=$ $101.52^{\circ}, \gamma=104.67^{\circ}$ ) for 3 . It is probably that the increase in weight observed during the TGA studies around $450{ }^{\circ} \mathrm{C}$ is due to the oxidation of $\mathrm{P}(\mathrm{III})$ to $\mathrm{P}(\mathrm{V})$, provoking the crystallization of 20 the mentioned inorganic phosphates. The thermal evolution of the cell parameters for $\mathbf{1}$ and $\mathbf{3}$ was determined by pattern matching analysis (Fig. S9). The volume of the phases exhibits a constant increase with thermal expansion coefficients around $40 \cdot 10^{-6}$ and $34 \cdot 10^{-6}{ }^{\circ} \mathrm{C}^{-1}$ in the $30-195^{\circ} \mathrm{C}$ temperature range.

\section{${ }_{25}$ Infrared, UV-Vis, XPS and Mössbauer spectroscopy}

In the infrared spectra of the three compounds (Fig. S10), the organic template is mainly represented by a group of overlapped maxima corresponding to stretching vibrations $(v)$ of $\mathrm{N}-\mathrm{H}$ and $\mathrm{C}-$ $\mathrm{H}$ bonds in the $3100-2500 \mathrm{~cm}^{-1}$ region. The $\delta\left(\mathrm{NH}_{3}{ }^{+}\right)$band appears 30 at $1600 \mathrm{~cm}^{-1}$, indicating that the organic molecules are protonated and not coordinated to the inorganic building.

Regarding the inorganic part, around $2400 \mathrm{~cm}^{-1}$ a narrow band split in two ones, corresponding to the stretching vibrational mode of the $\mathrm{P}-\mathrm{H}$ bond from the $\left(\mathrm{HPO}_{3}\right)^{2-}$ groups can be observed 35 in the spectra. At lower frequencies, in the $1100-400 \mathrm{~cm}^{-1}$ range, the bands corresponding to the $\mathrm{P}-\mathrm{O}$ bonds vibrations of the phosphite/phosphate groups are observed. The $v(\mathrm{O}-\mathrm{H})$ absorption band related to the coordinated water molecules is also observed at around $3420 \mathrm{~cm}^{-1}$.

40 The diffuse reflectance spectra of $\mathbf{1 , 2}$ and $\mathbf{3}$ show mainly four bands (Fig. 4). In the diffuse reflectance spectrum of $\mathbf{1}$, two bands at approximately 10640 and $7520 \mathrm{~cm}^{-1}$ are observed. These bands are characteristic of the iron(II) $d^{6}$-high spin cation in a slightly distorted octahedral environment, and correspond to the

${ }_{45}$ electronic transitions from the ${ }^{5} \mathrm{~T}_{2 \mathrm{~g}}\left({ }^{5} \mathrm{D}\right)$ fundamental state to the excited level ${ }^{5} \mathrm{E}_{2 \mathrm{~g}}\left({ }^{5} \mathrm{D}\right)$ that is splitted as a consequence of the existence of the non-regular $\left[\mathrm{M}(3) \mathrm{O}_{4} \mathrm{~F}_{2}\right]$ and $\left[\mathrm{M}(4) \mathrm{O}_{2}\left(\mathrm{H}_{2} \mathrm{O}\right)_{2} \mathrm{~F}_{2}\right]$ octahedra. The energy associated with this transition corresponds, according to the Tanabe-Sugano diagram ${ }^{54}$ to the $D q$ parameter. so The value obtained is $D q=910 \mathrm{~cm}^{-1}$. An overlapped band situated around $13510 \mathrm{~cm}^{-1}$ which corresponds to the forbidden transition from the ${ }^{6} \mathrm{~A}_{1 \mathrm{~g}}\left({ }^{6} \mathrm{~S}\right)$ ground state to the ${ }^{4} \mathrm{~T}_{1 \mathrm{~g}}\left({ }^{4} \mathrm{G}\right)$ term is attributed to the presence of iron(III) $d^{5}$-high spin configuration cations. ${ }^{55} \mathrm{An}$ intense band can also be observed at approximately $18180 \mathrm{~cm}^{-1}$. ${ }_{55}$ This band is likely to correspond to the intervalence transition between the $\mathrm{Fe}^{2+}$ and $\mathrm{Fe}^{3+}$ cations, because their polyhedra share the four crystallographically independent fluorine atoms and the intermetallic bond distance are short enough (between 3.57 and
$3.69 \AA) .{ }^{27}$ In the spectra of 2 and $\mathbf{3}$ compounds the discrimination 60 of the transition bands characteristic of the $\mathrm{Co}^{2+}$ cations is not a clear task because of the overlapping of different $d^{5}, d^{6}$ and $d^{7}$ high spin cations signals. However, these spectra show a significant change in the relative intensity of the splitted ${ }^{5} \mathrm{~T}_{2 \mathrm{~g}}\left({ }^{5} \mathrm{D}\right)$

${ }^{5} \mathrm{E}_{2 \mathrm{~g}}\left({ }^{5} \mathrm{D}\right)$ transition bands as well as a reduction in the intensity ${ }_{65}$ of the $t_{2 g}\left(\mathrm{Fe}^{2+}\right) \rightarrow t_{2 g}\left(\mathrm{Fe}^{3+}\right)$ intervalence transition, suggesting an effective substitution of $\mathrm{Fe}(\mathrm{II})$ by $\mathrm{Co}(\mathrm{II})$.

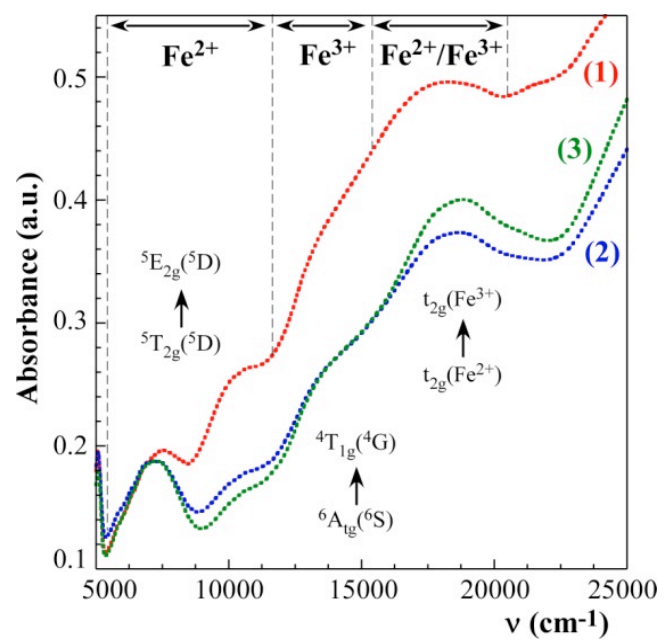

Fig. 4. UV-Vis spectra of iron (II)-(III) 1 (in red) and cobalt(II)substituted $\mathbf{2}$ (in blue) and $\mathbf{3}$ (in green) complexes.

70 The chemical composition and the possible oxidation state of the iron and cobalt metals of the upper layers in these compounds were investigated by XPS measurements. The fitting together with the binding energies of the N 1s, P $2 p, F 1 s, F e ~ 2 p$ and Co $2 \mathrm{p}_{1 / 2}$ peaks are deposited as Supplementary material (Fig. S11).

75 The N 1s peaks are resolved into two peaks at around 399 and $401 \mathrm{eV}$ which could be attributed to the existence of two primary and two secondary protonated amines per organic molecule. The P $2 p$ peaks are deconvoluted into two doublets registered at binding energies between 130 and $133 \mathrm{eV}$ and assigned to $\mathrm{P}(\mathrm{III})$ 80 species, which used to be lower than observed for $\mathrm{P}(\mathrm{V})$ species. ${ }^{56}$ The F 1s peak centered at around $684 \mathrm{eV}$ may be attributed to the metal-fluorine bonds. ${ }^{57}$ The decomposition of $\mathrm{Fe} 2 \mathrm{p}_{3 / 2}$ spectra for compound 1 suggests the coexistence of $\mathrm{Fe}^{2+}$ close to $711 \mathrm{eV}$ and $\mathrm{Fe}^{3+}$ at around $714 \mathrm{eV}$ according to the values found for $\mathrm{FeF}_{2}$. and ${ }_{85} \mathrm{FeF}_{3}$ fluorides, respectively. ${ }^{58}$ Deconvolution of this region in compounds $\mathbf{2}$ and $\mathbf{3}$ is hindered by the interference of the Auger line Co LMM, however, the values of the Fe $2 p_{1 / 2}$ component close to 724 and $727 \mathrm{eV}$, next to those found in 1, suggests also the mixed valency of the iron cations. Moreover, it is important to 90 note the absence of the satellite peak of the Fe $2 p$ as it has been previously reported for the mixed valence iron oxide $\mathrm{Fe}_{3} \mathrm{O}_{4}{ }^{59}$ Likewise, compounds 2 and $\mathbf{3}$ show a Co $2 \mathrm{p}_{1 / 2}$ main line at a binding energy around $797 \mathrm{eV}$, which is close to that found in a recently published cobalt(II) hybrid phosphite. ${ }^{60}$ The presence of ${ }_{95}$ the strong satellite peak at about $6 \mathrm{eV}$ from the Co $2 \mathrm{p}_{1 / 2}$ component is a further evidence for $\mathrm{Co}^{2+}$ species. ${ }^{61}$

The powder ${ }^{57} \mathrm{Fe}$ room temperature Mössbauer spectra of the three compounds were studied as shown in Fig. 5. The best fit of 1, 2 and 3 leads to one doublet for iron(III) cations and another 100 one for iron(II), obtaining $\mathrm{Fe}^{3+} / \mathrm{Fe}^{2+}$ area ratios of $1.35,2.80$ and 
3.20 respectively. The values of the isomer shift and quadrupolar splitting parameters given in Table 2 show the characteristic values for the $\mathrm{Fe}^{3+}$ and $\mathrm{Fe}^{2+}$ cations. Given the multiplicity of the four crystallographically independent positions for the iron atoms 5 and the metal-ligand distances obtained from the single-crystal structure analysis of compound $\mathbf{1}$, the $\mathrm{Fe}^{3+}$ are distributed over the positions $\mathrm{Fe}(1)$ and $\mathrm{Fe}(2)$ and the $\mathrm{Fe}^{2+}$ in the $\mathrm{M}(3)$ and $\mathrm{M}(4)$ positions. However, the percentage of $\mathrm{Fe}^{3+}$ exceeds $50 \%$, so we interpret that a partial substitution of $\mathrm{Fe}$ (II) by $\mathrm{Fe}$ (III) (Occ. = 10 0.296) occurs in the $\mathrm{M}(3)$ position (Fig. 6) as this presents a less variation of the metal-ligand distances range than the $\mathrm{M}(4) \mathrm{O}_{2}\left(\mathrm{H}_{2} \mathrm{O}\right)_{2} \mathrm{~F}_{2}$ octahedron.

Taking into account the structural features of compound $\mathbf{2}$, it is assumed that the $\mathrm{Fe}^{3+}$ ions occupy only the $\mathrm{Fe}(1)$ and $\mathrm{Fe}(2)$ 15 positions. Therefore, considering the amount of cobalt obtained from the ICP-Q-MS analysis and the results from the structural refinement, the $\mathrm{Fe}^{2+}$ are totally replaced by $\mathrm{Co}^{2+}$ ions in the $\mathrm{M}(4)$ position and partially substituted in the $\mathrm{M}(3)$ position (Occ. =
0.290) (Fig. 6).

20 Table 2 Hyperfine parameters at $298 \mathrm{~K}$ ( $\delta$, isomer shift; $\Delta E$, quadrupolar splitting; \%, proportion of each component) for $\mathbf{1}, \mathbf{2}$ and $\mathbf{3}$

\begin{tabular}{|c|c|c|c|c|}
\hline & Position & $\boldsymbol{\delta}(\mathbf{m m} / \mathbf{s})$ & $\boldsymbol{\Delta E}(\mathbf{m m} / \mathbf{s})$ & (\%) \\
\hline \multirow{2}{*}{1} & $(\mathrm{Fe}(1)+\mathrm{Fe}(2))^{3+}$ & $0.313(1)$ & $0.42(1)$ & 57.4 \\
\cline { 2 - 5 } & $\left(\mathrm{M}(3)^{*}+\mathrm{M}(4)\right)^{2+}$ & $1.150(1)$ & $2.61(1)$ & 42.6 \\
\hline & $* 7.4 \%$ that exceeds the $50 \%$ of Fe$^{3+}$ occupies $\mathrm{M}(3)$ position \\
\hline \multirow{2}{*}{$\mathbf{2}$} & $(\mathrm{Fe}(1)+\mathrm{Fe}(2))^{3+}$ & $0.318(1)$ & $0.44(1)$ & 73.7 \\
\cline { 2 - 5 } & $\mathrm{M}(3)^{2+}$ & $1.165(1)$ & $2.62(1)$ & 26.3 \\
\hline \multirow{4}{*}{$\mathbf{3}$} & $(\mathrm{Fe}(1)+\mathrm{Fe}(2))^{3+}$ & $0.314(1)$ & $0.44(1)$ & 76.2 \\
\cline { 2 - 5 } & $\mathrm{M}(3)^{2+}$ & $1.187(1)$ & $2.57(1)$ & 23.8 \\
\hline
\end{tabular}
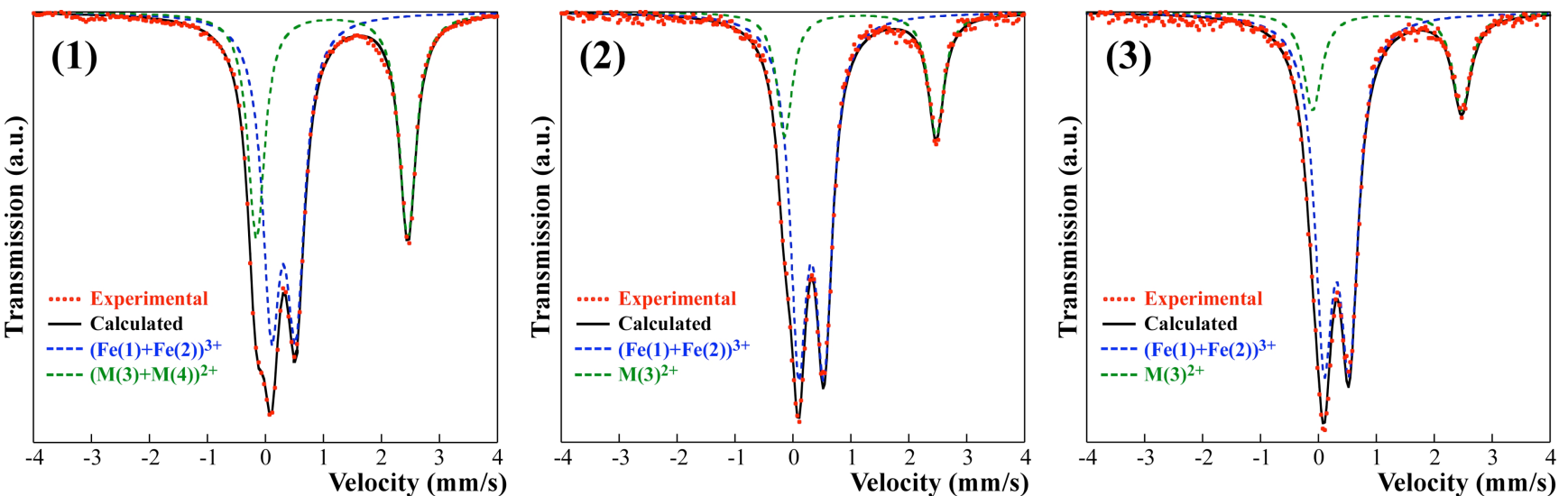

Fig. 5 Mössbauer spectra of 1, 2 and 3 at room temperature.

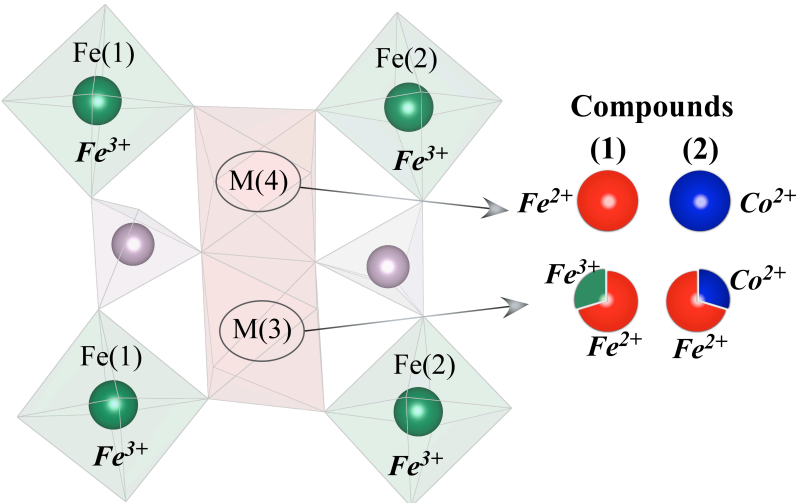

25 Fig. 6. Distribution of the $\mathrm{Fe}^{3+}, \mathrm{Fe}^{2+}$ and $\mathrm{Co}^{2+}$ cations inferred from the structural analysis and the Mössbauer study.

\section{Magnetic behaviour of 1 and 3}

Fig. 7 shows the temperature dependence of the molar magnetic susceptibility $\left(\chi_{\mathrm{m}}\right)$ and inverse susceptibility $\left(1 / \chi_{\mathrm{m}}\right)$ curves of 30 compounds $\mathbf{1}$ and $\mathbf{3}$, measured on powdered samples from room temperature to $2 \mathrm{~K}$, in the Field Cooling (FC) mode at $2 \mathrm{kOe}$.

The molar magnetic susceptibility of $\mathbf{1}$ and $\mathbf{3}$ continuously increases as temperature decreases, showing a typical paramagnetic behaviour above $40 \mathrm{~K}$. At lower temperatures, $\chi_{\mathrm{m}}$
35 curve of 1 reaches a width rounded maximum at approximately $28 \mathrm{~K}$, showing a minimum at $20 \mathrm{~K}$ and then increasing again with an inflection point close to $6 \mathrm{~K}$. A similar behaviour was observed in the compound $\mathrm{Co}_{2}(\mathrm{OH}) \mathrm{AsO}_{4}{ }^{62}$ However, the behaviour of $\mathbf{3}$ at low temperatures is somewhat different, in such 40 a way that the maximum which FC curve displays at $28 \mathrm{~K}$ is quite sharp, besides that the susceptibility decreases much more than $\mathbf{1}$ after the maximum, reaching a minimum at approximately $10 \mathrm{~K}$. Afterwards, $\chi_{\mathrm{m}}$ curve increases until $5 \mathrm{~K}$ without changes in curvature. These behaviours at low temperature do not ${ }_{45}$ correspond either to a typical ferromagnet or antiferromagnet, although it looks more like that observed in antiferromagnets, specially in 3.

The experimental data in both cases follow the Curie-Weiss law above $100 \mathrm{~K}$ (see lower insets in Fig. 7), allowing the s0 calculation of the Weiss temperature $(\mathbf{1}, \theta=-95.6 \mathrm{~K}$ and $\mathbf{3}, \theta=$ $125 \mathrm{~K})$ and the average effective paramagnetic moment per metal ion $\left(1, \mu_{\mathrm{eff}}=5.60 \mu \mathrm{B}\right.$ and $\left.\mathbf{3}, \mu_{\mathrm{eff}}=5.95 \mu \mathrm{B}\right)$. The value of $\mu_{\mathrm{eff}}$ for $\mathbf{1}$ is intermediate between the expected for $\mathrm{Fe}^{2+}\left(5.4 \mu_{\mathrm{B}}\right)$ and $\mathrm{Fe}^{3+}$ $\left(5.9 \mu_{\mathrm{B}}\right)$, whereas that for cobalt-substituted compound is slightly ${ }_{5}$ higher than the expected for $\mathrm{Fe}^{3+}$, probably because the Co ions present an extra contribution coming from the angular momentum. The negative Weiss temperatures together with the decrease of the $\chi_{\mathrm{m}} \mathrm{T}$ products with decreasing temperature indicate that the main magnetic interactions in these compounds 
are antiferromagnetic. The abrupt increase of the susceptibility below $20 \mathrm{~K}$ for $\mathbf{1}$ and the sharp maximum close to $28 \mathrm{~K}$ for $\mathbf{3}$ correspond to the onset of $\mathrm{AF}$ order, as will be described later from $\mathrm{M}(\mathrm{H})$ curves and heat capacity $(\mathrm{Cp})$ data.

The upper insets of Fig. 7 show the low temperature ZFC and FC molar susceptibility $\left(\chi_{\mathrm{m}}\right)$ details performed at $0.5,2$ and 10 kOe. For 1 a small irreversibility appears at 0.5 kOe below $30 \mathrm{~K}$ and although practically disappears for fields higher than $2 \mathrm{kOe}$, a tiny contribution persists up to $10 \mathrm{kOe}$. For $\mathbf{3}$ a small splitting of

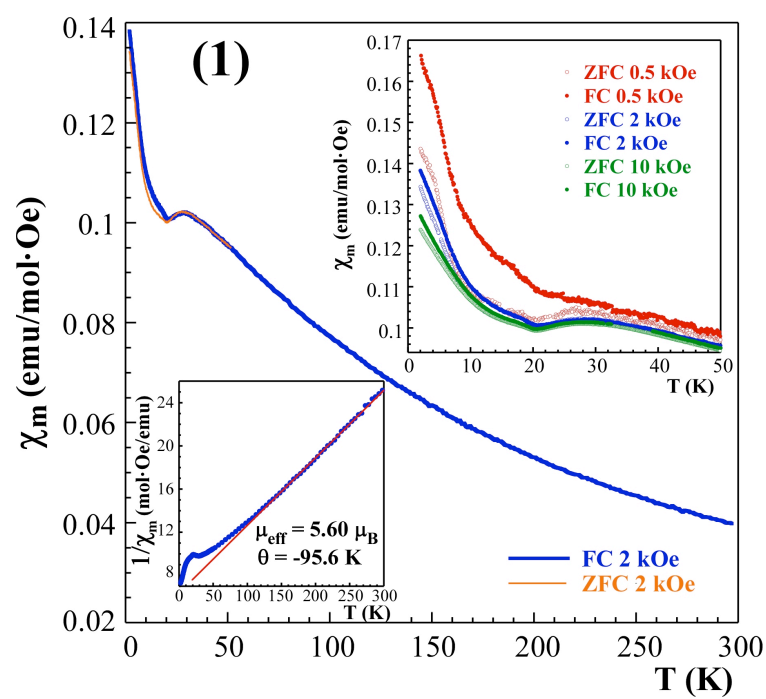

10 the curves can also be observed but whose intensity is much less dependent on the magnetic field than in the compound 1. Besides, the minimum location is reliant on the magnetic field, shifting from 9 to $16 \mathrm{~K}$ as increasing the field from 0.5 to $10 \mathrm{kOe}$ for 3 , while for 1 the position remains practically unchanged at $20 \mathrm{~K}$ 15 regardless of the applied field. The existence of irreversibility can only be attributed to the existence of a weak ferromagnetic component.

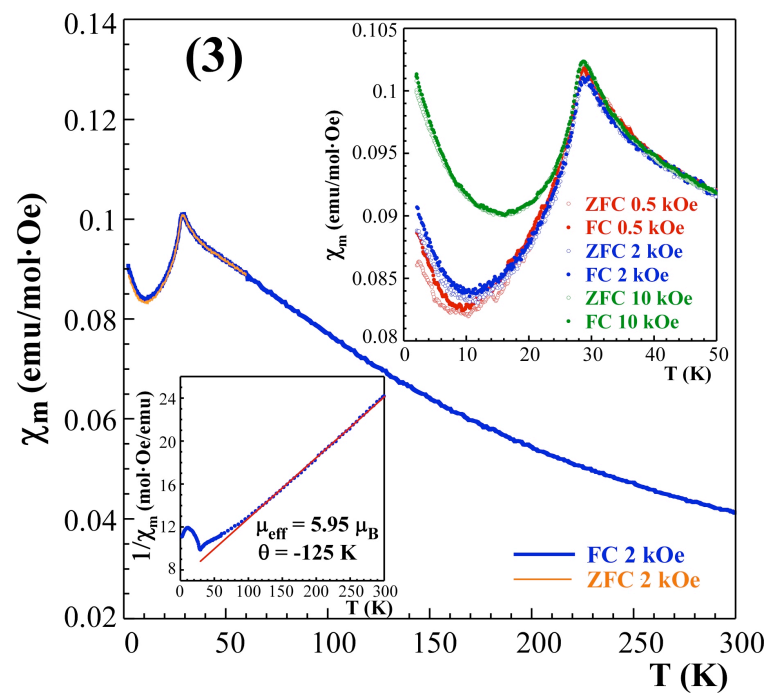

Fig. 7 Temperature dependence of $\chi_{\mathrm{m}}$ for compounds $\mathbf{1}$ and $\mathbf{3}$ measured under $2 \mathrm{kOe}$. The lower inset shows the $1 / \chi_{\mathrm{m}}$ curve fitted to the Curie-Weiss law 20 and the upper inset an enlargement of the low-temperature region of ZFC-FC data measured under 0.5, 2 and $10 \mathrm{kOe}$.

In Fig. $8 \mathrm{a}$ it is depicted the field dependence of the magnetization of $\mathbf{1}$ at different temperatures. At $2 \mathrm{~K}$, the magnetization increases almost linearly with the magnetic field until a critical field of $45 \mathrm{kOe}$, where a metamagnetic transition 25 occurs. The magnetization value $\left(0.45 \mu_{\mathrm{B}} / \mathrm{Fe}\right.$ ion $)$ obtained at the highest applied field, $90 \mathrm{kOe}$, is far from the theoretical saturation for the $\mathrm{Fe}(\mathrm{II})\left(4 \mu_{\mathrm{B}}\right)$ and $\mathrm{Fe}(\mathrm{III})\left(5 \mu_{\mathrm{B}}\right)$ ions, indicating the

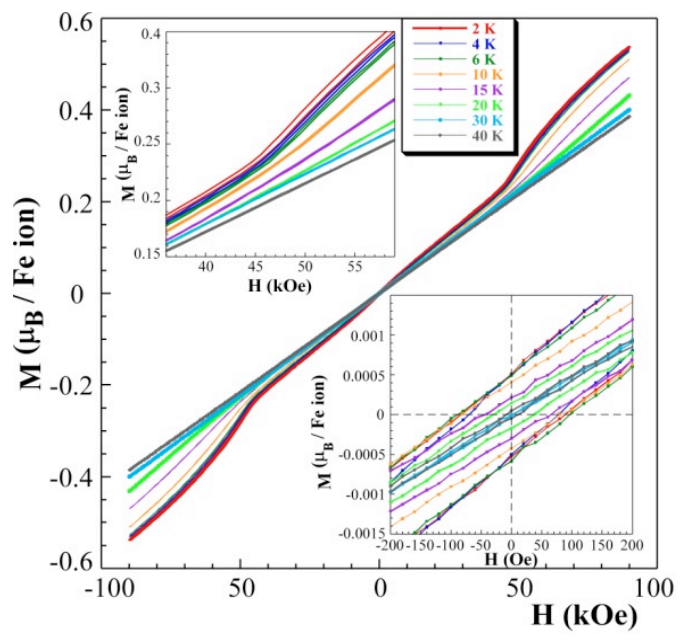

(a) existence of a strong magnetocrystalline anisotropy. Despite the $\mathrm{M}(\mathrm{H})$ general behaviour is characteristic of an antiferromagnetic 30 order, it is important to note the existence of an small hysteresis with a coercitive field of 85 Oe at low temperatures, which confirms the existence of a weak ferromagnetic component (lower inset in Fig 8a).

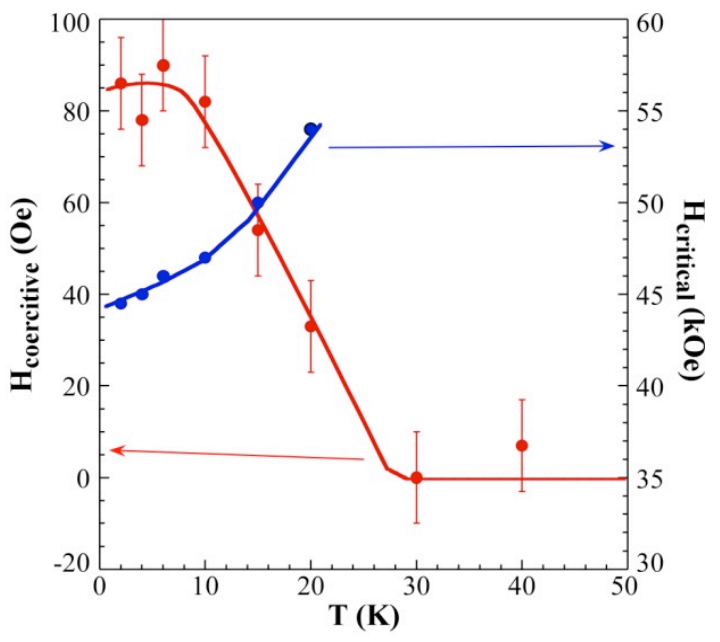

(b)

35 Fig. 8 a) Magnetization vs applied magnetic field at different temperatures for $\mathbf{1}$. The upper inset shows the detail of the metamagnetic transition and the lower inset an enlargement of the small coercitivity of the hysteresis loops. b) Thermal evolution of the coercitive field of the hysteresis loops and critical field of the metamagnetic transition. 
The hysteresis decreases as the temperature increases, disappearing in the paramagnetic region. The temperature increase also provokes a positive shift of the critical field of the metamagnetic transition (upper inset in Fig 8a). Above 20K, the 5 metamagnetic transition disappears as well as the $\mathrm{M}(\mathrm{H})$ curves are completely linear up to $90 \mathrm{kOe}$ (Fig. 8b). In the case of compound 3, the hysteresis loops do not show any significant remnant magnetization. However, there is also a critical field close to $62 \mathrm{kOe}$ at $2 \mathrm{~K}$ indicating the existence of a metamagnetic 10 transition (Fig. S12, Supplementary Material).

To get a further insight of the weak ferromagnetic component of 1 , we have measured the thermoremanent magnetization (TRM) as well as the ac magnetic susceptibility. The TRM curve was measured at $\mathrm{H}=0$ after cooling from $\mathrm{T} \geq \mathrm{T}_{\mathrm{N}}$ under a magnetic

15 field of $5 \mathrm{kOe}$. As can be observed in Fig. S13, the value decreases continuously as increase the temperature, reaching zero above the Neel temperature. The appearance of a positive remanent magnetization below $\mathrm{T}_{\mathrm{N}}$ confirms the existence of a weak ferromagnetic component. In addition, it is important to 20 signal the appearance of a clear shoulder at around $6 \mathrm{~K}$ as was also pointed out in the $\mathrm{FC}$ curve. The real $\left(\chi^{\prime}\right)$ and imaginary $\left(\chi^{\prime \prime}\right)$ components of the ac susceptibility at $1000 \mathrm{~Hz}$ with an ac field of 10 Oe are shown in Fig. S14. $\chi^{\prime}$ shows a broad maximum centred at $28 \mathrm{~K}\left(\mathrm{~T}_{\mathrm{N}}\right)$ whereas $\chi^{\prime \prime}$, which should be zero in 25 antiferromagnetic compounds, has a small contribution associated with the weak ferromagnetic component. Surprisingly a sharp peak emerges in both $\chi^{\prime}$ and $\chi^{\prime \prime}$ around $4.5 \mathrm{~K}$ indicating the presence o a magnetic transition of different nature from the previous one. This transition was masked in the magnetic 30 susceptibility by the weak ferromagnetic component but should be the responsible of the shoulder observed around $6 \mathrm{~K}$ in the FC and TMR curves. To check the origin of this low temperature transition we have measured the ac susceptibility at different frequencies (inset of Fig. S14). The peak height decreases and the 35 position of the maximum shifts to higher temperatures with increasing frequency, as usually happens in spin glass transitions. The spin glass nature of the transition is further confirmed by the absence of any anomaly at $4.5 \mathrm{~K}$ in the heat capacity data. The coexistence of antiferromagnetism and spin glass behaviours has

40 been previously observed in other insulator materials. ${ }^{23,63}$ This result could be due to the simultaneous but random presence of $\mathrm{Fe}(\mathrm{II})$ and $\mathrm{Fe}(\mathrm{III})$ cations in the $\mathrm{M}(3)$ position of compound 1 (Fig. 6), which gives rise to the competing interactions. Both randomness and competing interactions lead to spin frustration, ${ }_{45}$ ultimately resulting in the spin-glass state.

Considering the structural features of compounds $\mathbf{1}$ and $\mathbf{2}$, studied by single crystal X-ray diffraction, and taking into account that $\mathbf{3}$ is isotypic, several magnetic pathways can take place in these three phases. Inside the layers metal-metal ${ }_{50}$ distances range between 3.2 and $3.7 \mathrm{~A}^{\circ}$ and consequently direct interactions are not negligible. A view of the most important magnetic exchange interactions $\mathrm{M}-\mathrm{O}-\mathrm{M}$ and $\mathrm{M}-\mathrm{F}-\mathrm{M}$ in $\mathbf{1}$ and $\mathbf{2}$ is given in Fig. S15. $\mathrm{J}_{1}$ pathway represents direct intradimeric magnetic interactions via oxygen atoms between the $\mathrm{M}(3) \mathrm{O}_{4} \mathrm{~F}_{2}$ 55 and $\mathrm{M}(4) \mathrm{O}_{2}\left(\mathrm{H}_{2} \mathrm{O}\right)_{2} \mathrm{~F}_{2}$ polyhedra. The values of the bond angles for $\mathrm{J}_{1}$ are around $98^{\circ}$ and $100^{\circ}$, being able to lead to a ferromagnetic interaction inside the dimmers. However, $J_{2}$ to $J_{5}$ pathways imply superexchange interactions through fluorine atoms involving bond angles between approximately 124 and $60133^{\circ}$ and clearly indicating the existence of an antiferromagnetic coupling. The superexchange inter- and intralayer $\mathrm{M}-\mathrm{O}-\mathrm{P}-\mathrm{O}-\mathrm{M}$ interactions allows one to propagate the magnetic interactions giving rise to a three-dimensional magnetic system. The bond distances and angle values for the exchange pathways are very ${ }_{65}$ close for $\mathbf{1}$ and the cobalt substituted compounds $\mathbf{2}$ and $\mathbf{3}$. So, the differences in the magnetic properties from $\mathbf{1}$ to $\mathbf{3}$ cannot be explained from a structural point of view.

Taking into account that the $\mathrm{Co}^{2+}$ ions prefer the $\mathrm{M}(3) \mathrm{O}_{4} \mathrm{~F}_{2}$ and $\mathrm{M}(4) \mathrm{O}_{2}\left(\mathrm{H}_{2} \mathrm{O}\right)_{2} \mathrm{~F}_{2}$ octahedra, the substitution of $\mathrm{Fe}(\mathrm{II})\left(d^{6}\right)(\mathrm{S}=2)$ 70 by $\operatorname{Co}\left(d^{7}\right)(\mathrm{S}=3 / 2)$ in the framework of 1 modifies the nature of some magnetic interactions involving $\mathrm{J}_{1}$ pathway.

The specific heat curves represented in Fig. 9 show a small maximum centered at $20.5 \mathrm{~K}$ for $\mathbf{1}$ and a sharp magnetic peak at $28 \mathrm{~K}$ for 3 . Despite the anomaly observed for $\mathbf{1}$ does not have the 75 typical appeareance of a $\lambda$-type second-order transition peak as in the case of the cobalt containing compound, it can be associated with the establishment of a three-dimensional antiferromagnetic order in good arrangement with the magnetic-susceptibility data. It is important to signal the absence of any additional anomaly at 80 low temperatures, confirming the spin glass nature of the transition observed in the ac susceptibility at $4.5 \mathrm{~K}$. The continuous growth of $\mathrm{Cp}$ at higher temperatures is due to the lattice contribution $\left(\mathrm{Cp}_{\text {pho }}\right)$, which does not show any tendency to saturation. In fact, the $\mathrm{Cp}$ values at $300 \mathrm{~K}$ for both compounds are 85 around $660 \mathrm{~J} / \mathrm{molK}$, still far from the expected values $(1,1287.8$ and 3, $1294.0 \mathrm{~J} / \mathrm{molK}$ ) according to the Dulong and Petit law for the 51.6 and 51.9 ions per unit formula for $\mathbf{1}$ and $\mathbf{3}$, respectively. This is due to the presence of light atoms with very high excitation energy.

90 In order to extract the magnetic contribution, $\mathrm{C}_{\mathrm{mag}}$, the $\mathrm{Cp}_{\text {pho }}$ was estimated using the Debye model and considering the existence of three Debye temperatures (the minimum number of free parameters that will allow us to fit the experimental data). In this way, if the number of atoms in the unit cell is $\mathrm{N}$, we suppose ${ }_{95} \mathrm{n}_{1}$ atoms with a Debye temperature $\theta_{\mathrm{D} 1}, \mathrm{n}_{2}$ atoms with a Debye temperature $\theta_{\mathrm{D} 2}$, and $\mathrm{n}_{3}=\left(\mathrm{N}-\mathrm{n}_{1}-\mathrm{n}_{2}\right)$ atoms with a Debye temperature $\theta_{\mathrm{D} 3}$. Therefore, there are five free parameters, namely, $\mathrm{n}_{1}, \mathrm{n}_{2}, \theta_{\mathrm{D} 1}, \theta_{\mathrm{D} 2}$, and $\theta_{\mathrm{D} 3}$. This approach has been used successfully in previous studies in other hybrid compounds. ${ }^{64}$ The 100 best fittings are obtained for $\mathrm{n}_{1}=10.2, \theta_{\mathrm{D} 1}=213 \mathrm{~K}, \mathrm{n}_{2}=15.6$, $\theta_{\mathrm{D} 2}=650 \mathrm{~K}$ and $\theta_{\mathrm{D} 3}=2350 \mathrm{~K}$ for compound $1(\mathrm{~N}=51.6)$ and $\mathrm{n}_{1}=$ $10.9, \theta_{\mathrm{D} 1}=232 \mathrm{~K}, \mathrm{n}_{2}=15.6, \theta_{\mathrm{D} 2}=689 \mathrm{~K}$ and $\theta_{\mathrm{D} 3}=2578 \mathrm{~K}$ for compound $3(\mathrm{~N}=51.9)$. The good quality of the fits (see the continuous lines in Fig. S.16) allows us to consider that this 105 phenomenological model determines reasonably well the phonon contribution. The magnetic contribution, obtained as $\mathrm{Cp}_{\mathrm{mag}}=\mathrm{Cp}$ 
- $\mathrm{Cp}_{\text {pho }}$, is plotted in the insets of Fig. S16 (a) and (b) for compounds 1 and 3 respectively. The value of $\mathrm{Cp}_{\mathrm{mag}}$ in the maximum is clearly larger for $\mathbf{3}, 46.5 \mathrm{~J} / \mathrm{mol} \mathrm{K}$, than for $\mathbf{1}, 34.5$ $\mathrm{J} / \mathrm{mol} \mathrm{K}$. In addition, whereas for $3 \mathrm{Cp}_{\mathrm{mag}}$ has a $\lambda$-peak shape, for ${ }_{5} \mathbf{1}, \mathrm{Cp}_{\mathrm{mag}}$ has a triangular shape, extending up to $60 \mathrm{~K}$. These findings also indicates that compound $\mathbf{1}$ has a more complex magnetic structure than compound $\mathbf{3}$.

Heat-capacity has been also studied in the presence of several magnetic fields. With increasing field for $\mathbf{3}$, the sharp $\lambda$-type

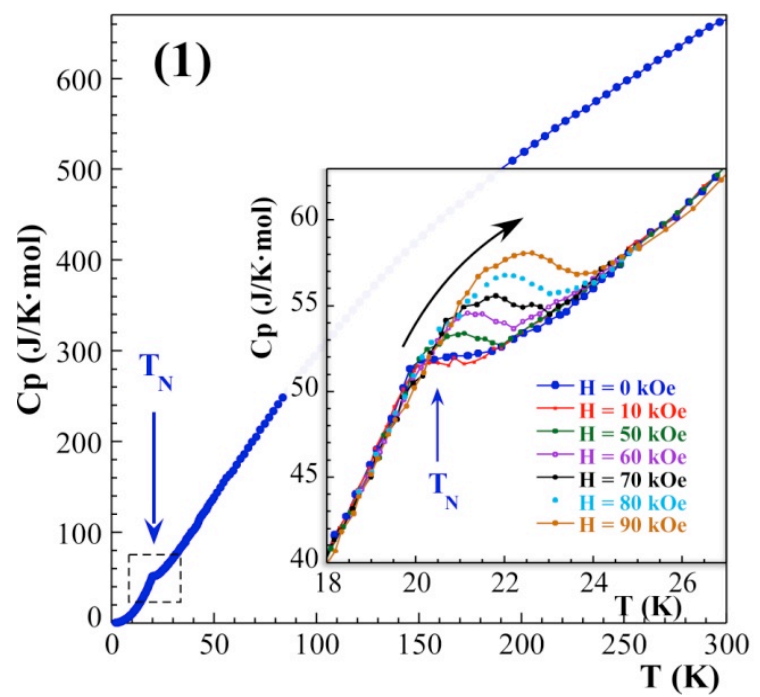

10 magnetic peak becomes more rounded and shifts to lower temperatures, what is in good agreement with a global antiferromagnetic behaviour as was also observed from the magnetic susceptibility. In the case of compound $\mathbf{1}$, an unexpected behaviour was observed. The small maximum shifts 15 to higher temperatures, grows with the magnetic field and becomes better defined. Usually, the effect of the magnetic field on ferromagnetic transitions consists of shifting the $\lambda$ anomaly to higher temperatures making it more rounded and less height.

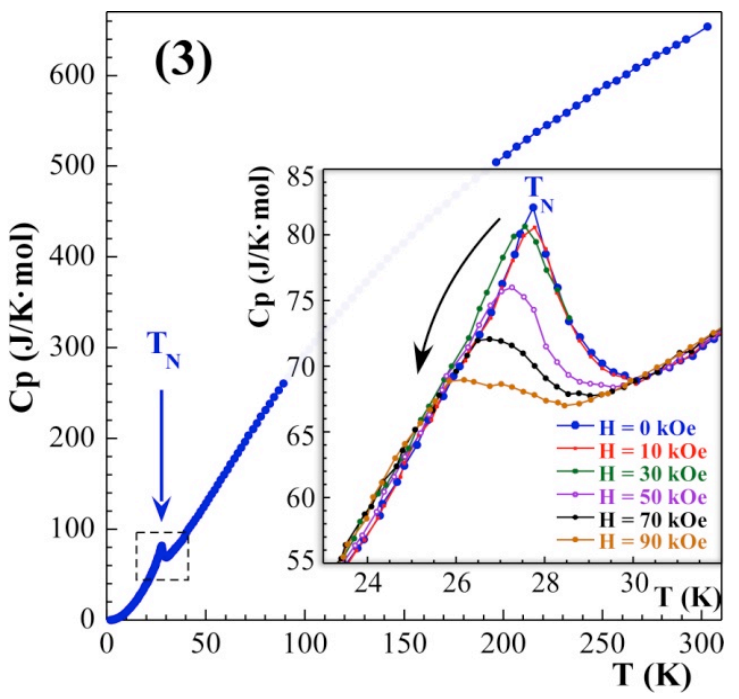

Fig. 9 Specific heat of compounds 1 and $\mathbf{3}$ between 2 and $300 \mathrm{~K}$. The insets show an enlargement around the Neel temperature as a function of temperature in the presence of external magnetic fields, $\mathrm{H}$, in the 0-90 kOe range.

Therefore, the small value of the anomaly observed in $\mathbf{1}$ could be associated with an incommensurate magnetic structure, in which the entropy difference with the paramagnetic state is lower 25 than in commensurate structures. The proposal of this kind of structure is also supported by the behaviour of the anomaly with the applied magnetic field. A similar behaviour of the specific heat anomaly was observed in the compound $\mathrm{Co}_{2}(\mathrm{OH}) \mathrm{AsO}_{4},{ }^{62}$ and in that case it was interpreted as an evolution of the magnetic 30 structure to the commensurability.

\section{Conclusions}

The mild hydrothermal technique was used for the synthesis of three novel 3D open-framework fluorinated mixed valence $\mathrm{Fe}(\mathrm{II})-\mathrm{Fe}(\mathrm{III})$ phosphites with channels templated by protonated 35 tetramine chains. The combined information from chemical analysis, X-ray diffraction and Mössbauer spectroscopy has allowed us to determine the $\mathrm{Fe}^{3+}, \mathrm{Fe}^{2+}$ and $\mathrm{Co}^{2+}$ cation distribution over the four metal sites. While $\mathrm{Fe}(1)$ and $\mathrm{Fe}(2)$ positions have a full occupancy of $\mathrm{Fe}^{3+}$ in the three phases, $\mathrm{M}(4)$ 40 is occupied by $\mathrm{Fe}^{2+}$ in $\mathbf{1}$ but totally replaced by $\mathrm{Co}^{2+}$ in $\mathbf{2}$ and $\mathbf{3}$. $\mathrm{M}(3)$ position presents partial occupations: $0.30 \mathrm{Fe}^{3+}: 0.70 \mathrm{Fe}^{2+}$ for $1,0.29 \mathrm{Co}^{2+}: 0.71 \mathrm{Fe}^{2+}$ for 2 and $0.38 \mathrm{Co}^{2+}: 0.62 \mathrm{Fe}^{2+}$ for 3 .

The average structure resolution of 1 neglecting the satellite intensity leaves electron density peaks above $\pm 3 \mathrm{e}^{-} \cdot \AA^{-3}$, which are 45 found at the equatorial plane of the $\left[\mathrm{M}(4) \mathrm{O}_{2} \mathrm{~F}_{2}\left(\mathrm{H}_{2} \mathrm{O}\right)_{2}\right]$ octahedron and near the nitrogen $\mathrm{N}(2)$ atom belonging to the organic template. The reciprocal analysis of $\mathbf{1}$ shows satellite reflections, described by a $q=0.284(2) \mathrm{a}^{*}$, which are the result of an incommensurate long-range order involving the crystallographic
${ }_{50}$ [100] direction. It is logical to think that the incommensurate structure is related to an incommensurate disorder of the organic molecule located along the [100] channels within the inorganic framework. This long-range order of the template seems to affect also the inorganic skeleton, because of the extensive network of 55 hydrogen bonds, as it is deduced from the residual electron densities located near the $\mathrm{M}(4)$ and $\mathrm{P}(4)$ sites. This incommensurability is not observed in $\mathbf{2}$. Therefore, while the template movement along the $a$ axis describes a structural modulation of the structure of $\mathbf{1}$, in $\mathbf{2}$ has not a periodic character, 60 only observing local disorders.

Magnetic measurements of $\mathbf{1}$ and $\mathbf{3}$ are consistent with the existence of major antiferromagnetic interactions. Compound $\mathbf{1}$ also exhibits weak ferromagnetism at low temperature and an additional spin glass transition at the freezing temperature $\mathrm{T}_{\mathrm{f}}=$ ${ }_{65} 4.5 \mathrm{~K}$. Despite the expected increase in random magnetic interactions with Co substitution because of its anisotropic nature, the freezing temperature and the weak ferromagnetism disappears in compound 3. So, the presence of $\mathrm{Co}(\mathrm{II})$ ions in both $\mathrm{M}(3)$ and M(4) sites can eliminate the magnetic frustration. Specific heat 70 curves show a small anomaly at $20.5 \mathrm{~K}$ for $\mathbf{1}$ and a sharp magnetic peak at $28 \mathrm{~K}$ for 3 . Strikingly, the anomaly observed in 1 grows with the magnetic field and becomes better defined. Such characteristics as the low value and its behaviour with the applied magnetic field suggest that this is due to the existence of an 75 incommensurate magnetic structure as was interpreted in compound $\mathrm{Co}_{2}(\mathrm{OH}) \mathrm{AsO}_{4}{ }^{62}$

Finally, given the features observed in the structural analysis matching the existence of a structural modulation along the [100] 
direction, it seems inevitable to think about the existence of some kind of relationship between this and the phenomenon observed in the study of the specific heat of the compound 1. In fact, the existence of electron density peaks located in the $\mathrm{M}(4)$ site, 5 occupied by $\mathrm{Fe}(\mathrm{II})$ cations, leads us to tentatively associate the incommensurate magnetic structure of $\mathbf{1}$ to a modulation of mixed valence $\mathrm{Fe}(\mathrm{III})-\mathrm{Fe}(\mathrm{II})$ cations. It should be recalled that $\mathrm{M}(4)$ site is totally occupied by Co(II) ions and does not show residual maxima around in phase 2

\section{${ }_{10}$ Acknowledgments}

This work has been financially supported by the "Ministerio de Ciencia e Innovación" (MAT2010-15375 and MAT2011-27573C04), the "Gobierno Vasco" (IT630-13) and the "UPV/EHU" (UFI11/15), which we gratefully acknowledge. The authors thank 15 the technicians of SGIker (UPV/EHU), financed by the National Program for the Promotion of Human Resources within the National Plan of Scientific Research, Development and Innovation, "Ministerio de Ciencia y Educación" and "Fondo Social Europeo" (FSE), for the X-ray diffraction, XPS, chemical 20 and spectroscopic measurements. J. Orive wish to thank the Universidad del País Vasco, UPV/EHU for funding.

\section{Notes and references}

${ }^{a}$ Departamento de Mineralogía y Petrología, Facultad de Ciencia y Tecnología, Universidad del País Vasco (UPV/EHU), Apdo. 644, 48080 25 Bilbao, Spain. Fax:+34 946013 500; Tel: +34 946015 984; E-mail: joseba.orive@ehu.es,roberto.fernandez@ehu.es, maribel.arriortua@ehu.es.

${ }^{b}$ CITIMAC, Facultad de Ciencias, Universidad de Cantabria, 39005 Santander, Spain. Fax:+34 942201 402; Tel: +34 942201 511; E-mail: 30rodrigufj@unican.es.

${ }^{c}$ Departamento de Electricidad y Electrónica, Facultad de Ciencia y Tecnología, Universidad del País Vasco (UPV/EHU), Apdo. 644, 48080 Bilbao, Spain. Fax:+34 946013 500; Tel: +34 946015 940; E-mail: estibaliz.legarra@ehu.es,fernando.plazaola@ehu.es.

$35 \dagger$ Electronic Supplementary Information (ESI) available:

View of the reciprocal space and reconstruction of the h0l layers of $\mathbf{1}$ and 2, conformers A and B of the organic molecule, Rietveld structure analysis of $\mathbf{3}$, thermal ellipsoid plots of $\mathbf{1}$ and $\mathbf{2}$, thermal analysis, infrared spectra, XPS spectra, magnetization $v s$ applied magnetic field at different

40 temperatures for $\mathbf{3}$, thermoremnant magnetization and ac magnetic susceptibility for 1, magnetic pathways and thermal evolution of $\mathrm{Cp}$, Cphon, and Cmag of phases $\mathbf{1}$ and 3. CCDC 978254 and 978255 . See DOI: $10.1039 / \mathrm{b} 000000 \mathrm{x} /$

1 D. Maspoch, D. Ruíz-Molina, J. Veciana, Chem. Soc. Rev., 2007, 36, 770 .

2 S. Natarajan, S. Mandal, Angew. Chem. Int. Ed., 2008, 47, 4798.

3 M. E. Davis, Nature, 2002, 417, 813; E. R. Parnham and R. E. Morris, Acc. Chem. Res., 2007, 40, 1005; J. Jiang, J. Yu and A. Corma, Angew.Chem., Int. Ed., 2010, 49, 3120.

4 J. Yu, R. Xu, Accounts Chem. Res., 2010, 43(9), 1195.

5 T. Loiseau, G. Férey, J. Mater. Chem., 1996, 6, 1073; C. Sassoye, J. Marrot, T. Loiseau, G. Ferey, Chem. Mater., 2002, 14, 1340.

6 J. Orive, E. S. Larrea, R. Fernández de Luis, M. Iglesias, J. L. Mesa, T. Rojo, M. I. Arriortua, Dalton Trans., 2013, 42, 4500; H-L. Huang, S-L. Wang, Chem. Commun., 2010, 46, 6141.

7 Y. Yang, N. Li, H. Song, H. Wang, W. Chen, S. Xiang, Chem. Mater., 2007, 19, 1889. J. Li, L. Li, J. Liang, P. Chen, J. Yu, Y. Xu,
R. Xu, Cryst. Growth Des., 2008, 8(7), 2318; J. Liang; J. Li, J. Yu, P. Chen, Q. Fang, F. Sun, R. Xu, Angew. Chem. Int. Ed., 2006, 45, 2546.

8 R. Chao, Y. Kong, L. Jin, Y. Ren, Y. Ding, N. Li, N. Guan, S. Xiang, Microporous Mesoporous Mater., 2013, 176, 132.

9 H-Y. Lin, C-Y. Chin, H-L. Huang, W-Y. Huang, M-J. Sie, L-H. Huang, Y-H. Lee, C-H. Lin, K-H. Lii, X. Bu, S-L. Wang, Science, 2013, 339, 811 .

10 P. Feng, X. Bu, G. D. Stucky, Nature, 1997, 388, 735; X. Bu, P. Feng, G. D. Stucky, J. Am. Chem. Soc., 1998, 120, 11204.

11 A. Choudhury, S. Natarajan, C. N. R. Rao, Inorg. Chem., 2000, 39, 4295.

12 S. Natarajan, Chem. Commun., 2002, 780.

13 J. A. Rodgers, W. T. A. Harrison, J. Mater. Chem., 2000, 10, 2853.

14 W-M. Chang, M-Y. Cheng, Y-C. Liao, M-C. Chang, S-L. Wang, Chem. Mater., 2007, 19, 6114.

15 M. E. Davis, R. F. Lobo, Chem. Mater., 1992, 4, 756.

16 D. W. Lewis, D. J. Willock, C. R. A. Catlow, Nature, 1996, 382, 604; J. Li, J. Yu, R. Xu, Microporous Mesoporous Mater., 2007, 101, 406; R. Pophale, F. Daeyaert, M. W. Deem, J. Mater. Chem. A, 2013, 1, 6750 .

17 A. Lu, N. Li, Y. Ma, H. Song, D. Li, N. Guan, H. Wang, S. Xiang, Cryst. Growth Des., 2008, 8(7), 2377.

18 A. Lakiss, A. Simon-Masseron, F. Porcher, S. Rigolet and J. Patarin, Eur. J. Inorg. Chem., 2007, 25, 4043; X. Luo, D. Luo, M. Gong, Y. Chen, Z. E. Lin, CrystEngComm., 2011, 13, 3646; L. Xue, D. Luo, X. Luo, H. Zeng, Z. Lin, Solid State Sciences, 2013, 19, 80.

19 G-M. Wang, J-Q. Jiao, X. Zhang, X-M. Zhao, X. Yin, Z-H. Wang, Y-X. Wang, J-H. Lin, Inorg. Chem. Comm., 2014, 39, 94; L-M. Li, K. Cheng, F. Wang, J. Zhang, Inorg. Chem., 2013, 52(10), 5654; G. Wang, J. Li, X. Zhang, P. Wang, B. Pang, Z. Wang, Y. Wang, J. Lin, C. Pan, Dalton Trans., 2013, 42, 13084.

20 T. Rojo, J. L. Mesa, J. Lago, B. Bazán, J. L. Pizarro, M. I. Arriortua, J. Mater. Chem., 2009, 19, 3793.

21 W. Yang, J. Li, Q. Pan, H. Xing, Y. Chen, J. Yu, R. Xu, J. Mater. Chem., 2009, 19, 4523; S. Mandal, S. Natarajan, J. M. Grenèche, M. RiouCavellec, G. Férey, Chem. Mater., 2002, 14, 3751.

22 G. Paul, A. Choudhury, E. V. Sampathkumaran, and C. N. R. Rao, Angew. Chem. Int. Ed., 2002, 41(22), 4297.

23 U-C. Chung, J. L. Mesa, J. L. Pizarro, I. de Meatza, M. Bengoechea, J. Rodríguez Fernández, M. I. Arriortua, T. Rojo, Chem. Mater., 2011, 23, 4317.

24 B. Bazan, J. L. Mesa, J. L. Pizarro, A. Peña, M. I. Arriortua, T. Rojo, Z. Anorg. Allg. Chem., 2005, 631, 2026.

25 J. Orive, J. L. Mesa, E. Legarra, F. Plazaola, M. I. Arriortua, T. Rojo, J. Solid State Chem., 2009, 182, 2191.

26 Y. Fan, T. Song, G. Li, Z. Shi, G. Yu, J. Xu, S. Feng, Inorg. Chem. Commun., 2005, 8(8), 661.

27 S. Fernández-Armas, J. L. Mesa, J. L. Pizarro, M. I. Arriortua, T. Rojo, Mater. Res. Bull., 2007, 42(3), 544.

28 S. Fernández-Armas, J. L. Mesa, J. L. Pizarro; J. S. Garitaonandia, Arriortua, M. I. Arriortua, T. Rojo, Angew. Chem. Int. Edit., 2004, 43(8), 977.

29 F. Shiba, R. Fujishiro, T. Kojima, Y. Okawa, J. Phys. Chem. C, 2012, 116, 3394; 
30 Q. Lin, C. Lei, G. Tang, Q. Zhang, Y. He, Hyperfine Interact., 2013, 219, 95; E. Coronado, J. R. Galán-Mascarós, C. J. Gómez-García, V. Laukhin, Nature, 2000, 408, 447.

31 O. Sato, T. Iyoda, A. Fujishima, K. Hashimoto, Science, 1996, 172, 704.

32 J. -H. Park, E. Izmár, M. W. Meisel, Y. -D. Huh, F. Frye, S. Lane, D. R. Talham, Appl. Phys. Lett., 2004, 85, 3797; J. -H. Park, F. Frye, S. Lane, E. Izmár, Y. -D. Huh, D. R. Talham, M. W. Meisel, Polyhedron, 2005, 24, 2355.

33 T. Liu, Y-J. Zhang, S. Kanegawa, O. Sato, J. Am. Chem. Soc., 2010, 132, 8250; S. Gawali-Salunke, F. Varret, I. Maurin, C. Enachescu, M. Malarova, K. Boukheddaden, E. Codjovi, H. Tokoro, S. Ohkoshi, K. Hashimoto, J. Phys. Chem. B, 2005, 109, 8251; N. Shimamoto, S. Ohkoshi, O. Sato, K. Hashimoto, Inorg. Chem., 2002, 41, 678; A. Goujon, F. Varret, V. Escax, A. Bleuzen, M. Verdaguer, Polyhedron, 2001, 20, 1339

34 H-M. Hu, X-Y. Huang, H-S. Sun, D-L. Long, J-S. Huang, X-Z. You, J. Coord. Chem., 1999, 47, 531; I. P-Y. Shek, W-F. Yeung, T-C. Lau, J. Zhang, S. Gao, L. Szeto, W-T. Wong, Eur. J. Inorg. Chem., 2005, 364; J-e. Koo, D-h. Kim, Y-S. Kim, Y. Do, Inorg. Chem., 2003, 42, 2983; A. Escuer, R. Vicente, M. S. El Fallah, X. Solans, M. FontBardia, Inorg. Chim. Acta, 1996, 247, 85. R. Vicente, A. Escuer, J. Ribas, M. S. El Fallah, X. Solans, M. Font-Bardia, Inorg. Chem., 1993, 32, 1920.

35 J. Qiao, L. Zhang, Y. Yu, G. Li, T. Jiang, Q. Huo, Y. Liu, J. Solid State Chem., 2009, 182, 1929.

36 W. Yingua, J. Appl. Crystallogr., 1987, 20, 258.

37 A. C. T. North, D. C. Philips, F. S. Mathews, Acta Crystallogr., 1968, A24, 351 .

38 CrysAlisPro $C C D$ and RED, version 171.35.19; Oxford Diffraction, Ltd.: Oxford, U.K., 2011.

39 G. M. Sheldrick, SHELXS 97: Program for the Solution of Crystal Structures, University of Göttingen, Germany, 1977.

40 G. M. Sheldrick, SHELXL 97: Program for the Refinement of Crystal Structures, University of Göttingen, Germany, 1977.

41 L. J. Farrugia, J. Appl. Crystallogr., 1999, 32, 837.

42 E. Dowty, ATOMS: A Computer Program for Displaying Atomic Structures, Shape Software, 512 Hidden Valley Road, Kingsport, TN, 1993; K. Momma, F. Izumi, J. Appl. Crystallogr., 2008, 41, 653.

43 V. A. Blatov, IUCr CompComm. Newslett., 2006, 7, 4.

44 J. Rodríguez-Carvajal, Rietveld Pattern Matching Analysis of Powder Patterns, FULLPROF, 1994.

45 R. A. Brand, J. Lauer, D. M. Herlach, J. Phys F: Met. Phys., 1983, 13, 675 .

46 I. D. Brown, D. Altermatt, Acta Crystallogr., 1985, B41(4), 244.

47 S. Álvarez, D. Avnir, M. Llunel, M. Pinsky, New. J. Chem., 2002, 26, 996; M. Llunel, D. Casanova, J. Cirera, J.M. Bofill, P. Alemany, S. Álvarez, M. Pinski, D. Yatumir, SHAPE v1.la: Program for Continuous Shape Measure Calculations of Polyhedral Xn and MLn Fragments, 2003.

48 J. Loub, Acta Crystallogr., 1991, B47(4), 468.

49 X-C. Su, H-K. Lin, S. R. Zhu, L-H. Weng, X-B. Leng, Y-T. Chen, Supramol. Chem., 2002, 14, 41; H. B. Szczesniak, V. Patroniak, W. Radecka-Paryzek, M. Kubicki, Acta Cryst., 2009, C65, 371.

50 V. Patroniak, W. Radecka-Paryzek, M. Kubicki, Acta Cryst., 2008, C64, 511 .
51 E. V. Anslyn, D. A. Dougherty, "Modern Physical Organic Chemistry", University Science Books (2006).

52 A. L. Spek, J. Appl. Crystallogr., 2003, 36, 7; A. L. Spek, Acta Crystallogr., Sect. D: Biol. Crystallogr., 2009, 65, 148.

53 M. Ókeeffe, Acta Crystallogr., Sect. A: Cryst. Phys., Diffr., Theor. Gen. Crystallogr., 1979, 35, 772; V. A. Blatov, A. P. Shevchenko, V. N. Serezhkin, Acta Crystallogr., Sect. A: Found. Crystallogr., 1995, 51, 909; V. A. Blatov, A. P. Shevchenko, Acta Crystallogr., Sect. A: Found. Crystallogr., 2003, 59, 34.

54 Y. Tanabe, S. Sugano, J. Phys. Soc. Jpn., 1954, 9, 753.

55 U-C. Chung, J. L. Mesa, J. L. Pizarro, J. Rodríguez Fernández, J. Sánchez Marcos, J. S. Garitaonandia, M. I. Arriortua, T. Rojo, Inorg. Chem., 2006, 45(22), 8965.

56 V. V. Guliants, J. B. Benziger, S. Sundaresan, J. Catal., 1995, 156, 298.

57 X-Z. Liao, Y-S He, Z-F. Ma, X-M. Zhang, L. Wang, J. Power Sources, 2007, 174, 720.

58 J. F. Moulder, W. F. Stickle, P. E. Sobol, K. D. Bomben, "Handbook of X-ray Photoelectron Spectroscopy (XPS)”, Edited by J. Chastain, Published by Physical Electronics Division, Perkin-Elmer Corporation (1992-1995).

59 T. Yamashita, P. Hayes, Appl. Surf. Sci., 2008, 254, 2441.

60 X. Wang, Y. Yan, J. Wu, Z. Dong, L. Li, J Li, Z. Anorg. Allg. Chem., 2013, 639(12-13), 2343.

61 L. F. Liotta, G. Di Carlo, G. Pantaleo, A. M. Venezia, G. Deganello, Appl. Catal. B-Environ., 2006, 66, 217.

62 I. de Pedro, J. M. Rojo, J. Rodríguez Fernández, M. T. FernándezDíaz, T. Rojo, Phys. Rev. B, 2010, 81, 134431.

63 I. de Pedro, J. M. Rojo, J. M. Pizarro, J. Rodríguez Fernández, J. Sánchez-Marcos, M. T. Fernández-Díaz, M. I. Arriortua, T. Rojo, J. Mater. Chem., 2007, 17, 3915; I. de Pedro, J. M. Rojo, J. L. Pizarro, J. Rodríguez Fernández, J. Sánchez-Marcos, M. I. Arriortua, T. Rojo, J. Phys.: Condens. Matter, 2006, 18, 3767; J. M. Rojo, J. L. Mesa, L. Lezama, J. L. Pizarro, M. I. Arriortua, J. Rodríguez Fernández, G. E. Barberis, and T. Rojo, Phys. Rev. B, 2002, 66, 094406.

64 E. S. Larrea, J. L. Mesa, J. L. Pizarro, R. Fernández de Luis, J. Rodríguez Fernández, T. Rojo, M. I. Arriortua, Dalton Trans., 2012, 41, 14170. 